\title{
芴类化合物的研究新进展
}

\author{
霍延平 $*, a$ 方小明 ${ }^{a}$ 黄宝华 $*, a$ 张 焜 ${ }^{a}$ 聂晓李 ${ }^{a}$ 曾和平 $*, b$ \\ $\left({ }^{a}\right.$ 广东工业大学轻工化工学院 广州 510006) \\ ( ${ }^{b}$ 华南理工大学化学与化工学院 功能分子研究所 广州 510640)
}

\begin{abstract}
摘要 芴及其衍生物是一类重要的具有刚性平面联苯结构的化合物, 分子内含有较大的共轭体系, 这种特殊的刚性稠 环结构使芴类化合物表现出许多独特的光电性能及生物活性，在光电材料、医药等多领域具有潜在的广泛应用. 更为 重要的是芴类化合物易于进行结构修饰，在芴环上可方便地引入各种功能基，芴类衍生物的合成及其开拓芴类化合物 潜在的新用途，成为近些年来十分活跃的研究领域，且发展迅速. 结合自己的工作，参考国内外文献，全面综述了荡类 化合物在有机电致发光材料、双光子吸收材料、光致变色材料、太阳能电池材料和生物医药等领域的研究与开发新进 展, 并对其发展趋势作了展望.
\end{abstract}

关键词 芴; 有机发光材料; 太阳能电池; 双光子吸收; 光致变色; 生物传感器

\section{New Progress of Researches in Fluorene Compounds}

\author{
Huo, Yanping ${ }^{*, a}$ \\ Fang, Xiaoming ${ }^{a}$ \\ Huang, Baohua*,a \\ Zhang, Kun $^{a}$ \\ Nie, Xiaoli ${ }^{a}$ Zeng, Heping ${ }^{*, b}$ \\ ( ${ }^{a}$ School of Chemical Engineering and Light Industry, Guangdong University of Technology, Guangzhou 510006) \\ $\left({ }^{b}\right.$ Institute of Functional Molecular, School of Chemistry and Chemical Engineering, South China University of \\ Technology, Guangzhou 510640)
}

\begin{abstract}
Fluorene and its derivatives are important compounds, which have biphenyl structure with rigid plane, as well as large $\pi$-conjugated system. These special structures of fluorene compounds endow their distinct various functions, properties and biological activities, as well as wide potential application in photoelectrical materials, medicinal agents and so on. More importantly, the fluorene compounds are easily modified and various functional groups could be conveniently introduced into the fluorene ring. The syntheses of fluorene derivatives and their potential applications were extensively investigated and have been become highly active highlight in recent years, and the progress is quite rapid. Combining with our researches and referring other works from literatures, this paper systematically reviews the recent advance in the research and development of fluorene in organic electro-luminescence materials, two-photon absorbing materials, photochromic materials, solar cells, medicinal chemistry and so on. The perspectives of the foreseeable future are also presented.
\end{abstract}

Keywords fluorene; organic light emitting materials; solar cell; two-photon absorption; photochromic; biosensor

芴类化合物因其在光电材料、太阳能电池、生物医 药等多领域广阔的应用前景一直受到人们的青睐 ${ }^{[1 \sim 4]}$. 芴具有特殊的刚性平面联苯结构, 其衍生物表现出许多 独特的光电性能及生物活性. 芴类化合物结构(1)特点: (1)芴环是特殊的联苯结构, 具有较高的热稳定性和光 化学稳定性，固态芴的荧光量子效率高达 $60 \% \sim 80 \%$,
带隙能大于 $2.90 \mathrm{eV} ;(2)$ 分子内具有更大的共轭吸收波 长; (3)具有更明显的电致发光、光致发光(磷光和苂光) 现象; (4)其 2 位、 7 位以及 9 位碳上易于进行结构修饰 引人多种官能团; (5)芴本身是煤焦油的分离产品之一， 产量大，价格低廉，原料易得. 芴这些特殊结构使其衍 生物在诸如光电材料、生物、医药等领域具有潜在的广

\footnotetext{
*E-mail: tigerhuo1974@yahoo.com.cn; huangbaoh@163.com; hpzeng@scut.edu.cn

Received April 19, 2012; revised May 16, 2012; published online May 22, 2012.

Project supported by the National Natural Science Foundation of China (Nos. 21172047, 21071054), the Science and Technology Planning Project of Guangdong Province (Nos. 2008B010800030, 2009B091300045) and the Fundamental Research Funds for the Central Universities of South China Uviversity of Technology (No. 2009ZM0179).

国家自然科学基金(Nos. 21172047，21071054)、广东省科技(Nos. 2008B010800030，2009B091300045)和华南理工大学中央高校基本科研业务费(Nos. 2009ZM0179)资助项目.
} 
泛应用, 近些年来得到了广泛的研究与开发. 在光电材 料领域中, 芴类衍生物如高分子材料聚茀作为有机光电 材料, 已成为一种非常重要并被许多学者认为最有希望 商业化的蓝光材料 ${ }^{[5,6]}$. 近年来从理论和实验上寻找和 设计合成具有大的双光子吸收截面的分子材料成为当 前分子光子学领域的热点研究问题. 荡类衍生物因具有 较大的电子离域、高的苂光量子产率和好的光热稳定性, 成为一类备受关注的双光子吸收材料. 随着太阳能电池 器件的快速发展, 有机太阳能电池材料的开发越来越受 到人们的重视, 䓄类化合物因其空穴传输性能好, 能隙 高, 被逐渐应用于制备有机太阳能电池材料 ${ }^{[79]}$. 而在 生物领域, 已经有多种芴类衍生物作为生物传感元件, 其中水溶性聚芴衍生物作为荧光探针已经被成功应用 于基因检测、蛋白质/酶浓度及活性测定、抗原抗体识 别、细菌检测以及细胞成像等一系列研究, 引起了化学 家和生物学家的高度重视 ${ }^{[10,11]}$. 目前对芴类化合物的研 究与开发工作众多, 发展迅速, 备受关注, 结合我们小 组的研究工作, 本文从实际应用来分类综述了芴类化合 物在光电材料、生物、医药等诸领域的研究与开发新状 况.

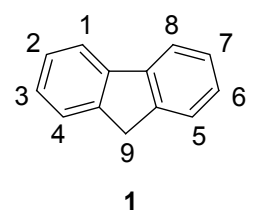

\section{1 在光电材料中的应用}

\section{1 有机电致发光材料}

有机电致发光材料由于具有材料选择广、能耗低、 效率和发光亮度高、超薄、全固化、响应速度快、主动 发光以及可大面积柔性显示等特点, 而有望成为新一代 平板显示技术的核心部件, 因而成为光电信息领域的研 究热点之一. 荡及其衍生物之所以能成为有机电致发光 材料中的明星分子, 主要是由于荡较宽的能隙和高的发 光效率等特点. 但是荡的电子亲合性小, 且聚䓄的溶解 性有限. 芴的 “绿色发射” 谱带的成因尚未被完全了解, 早期研究认为, 芴的 9 位碳原子又比较容易氧化而成为 羰基, 而羰基对由电子空穴复合产生的激子易形成 “陷 阱” 而有一定的 “猝灭” 作用, 最终会降低器件的发光 效率. 近期, Goel 等 ${ }^{[12,13]}$ 提出通过芴和芴酮及其相关支 架上的给体一受体部分的适当官能化而使绿光发射谱带 移动到蓝色区间来克服此缺陷的新概念/方法. 为了获 得不同发光颜色的发光材料 ${ }^{[14]}$, 调节芴基材料的发光 性能, 科学家们对䓄进行改性研究, 芴可以均聚也可以 与其他物质通过共聚共混改性. 对芴均聚物的改性主要 集中在芴的高反应活性的 9 位碳上. 引入的侧基通常为
脂肪碳链、芳香环或者其它基团. 引入的侧基一方面提 高了聚苆在有机溶剂中的溶解, 改善了最终材料的加工 成膜性能; 另一方面可以通过位阻来调节材料的聚集态 结构, 在一定温度范围里保持聚荡的晶型稳定，防止激 子在高分子主链之间传递淬灭，提高材料的发光效率.

\subsection{1 蓝光材料}

2007 年, Huang 等 ${ }^{[15]}$ 通过 Suzuki 聚合得到了交替共 聚物 2a 和 $\mathbf{2 b}$. 将二辛基苆引入聚茀的 9 位可以增加其 溶解度，同时具有屏蔽主链和减少主链䓄 9 位被氧化的 作用，三苯胺基团将有利于提高空穴在阳极界面的注入 能力.
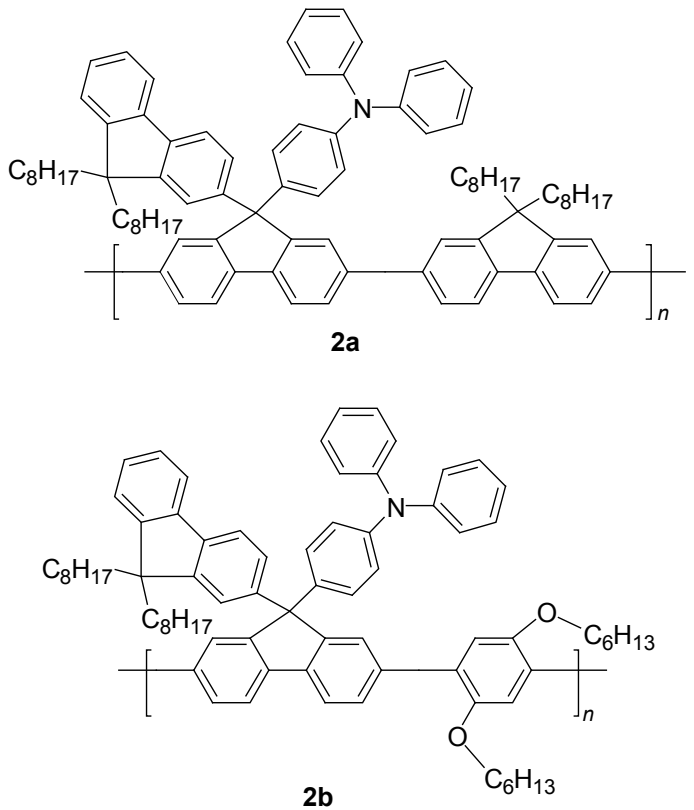

Yang 等 ${ }^{[16]}$ 通过 Suzuki 偶联反应，引入三苯胺合成 了螺旋芴基葟聚物 3 (Eq. 1), 螺环结构提高了玻璃化转 变温度 $\left(197 \sim 253{ }^{\circ} \mathrm{C}\right)$, 减弱了分子间作用力, 因此膜能 保持良好的形态稳定性, 同时获得很高的苂光量子效率 (0.98).

Chen 等 ${ }^{[17]}$ 通过三步偶联反应合成了由低聚荡片段 和推拉电子基团组成的蓝光聚合材料 $\mathbf{4}$, 这些材料更容 易实现空穴和电子的注入传输, 寡聚物 4 在氯仿溶液中 的光致发光量子产率(PLQY)为 $59 \% \sim 64 \%$, 并且随着 荡单元的增加, 光学性质发生显著变化, 能隙增加.

Liu 等 ${ }^{[18]}$ 通过利用一种带有含胺基侧链的二溴苯单 体和一种侧链有 6 个碳的芴的硼酸共聚，得到了第一个 聚荡类的共轭聚电解质 $\mathbf{5}$, 这种聚合物固态膜的荧光发 射峰在 $424 \mathrm{~nm}$, 为典型的聚茀蓝光. 随后他们又通过控 制聚合物侧链上胺基的季铵盐化程度, 研究了聚合物季 铵盐程度对荧光性能的影响, 发现随着聚合物季铵盐化 程度的提高, 聚合物无论是在溶液中还是薄膜状态下的 苂光都发生逐渐的蓝移 ${ }^{[19]}$ 


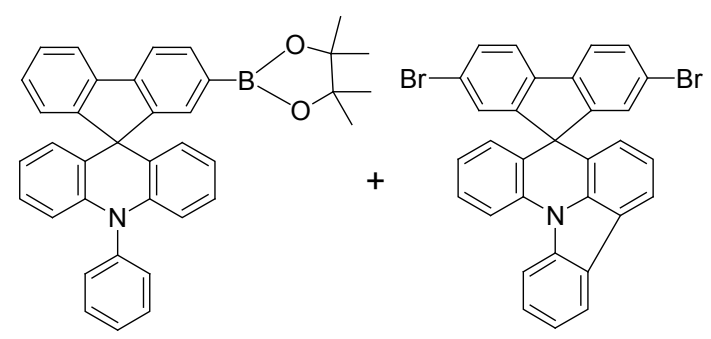

$\mathrm{Pd}\left(\mathrm{PPh}_{3}\right)_{4} / \mathrm{K}_{2} \mathrm{CO}_{3} \downarrow \mathrm{H}_{2} \mathrm{O} / \mathrm{THF}$

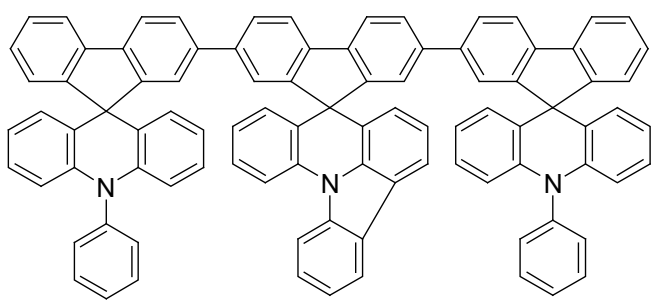

(1)

3
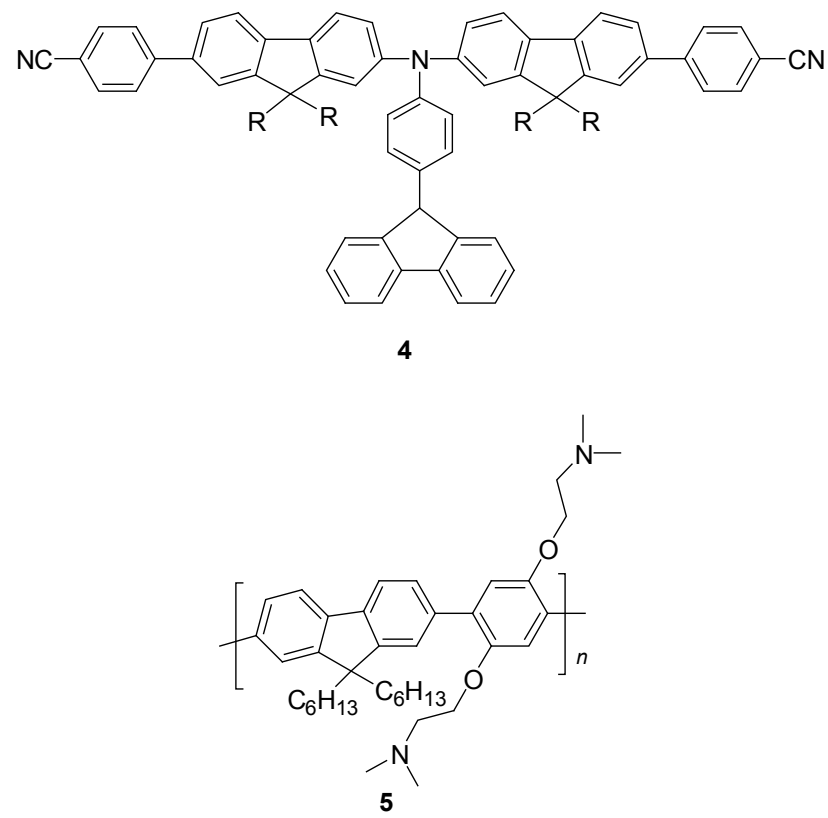

2012 年, Huang 等 ${ }^{[20]}$ 报道了一系列以螺二芴为核的 双功能聚合物, 其中聚合物 $\mathbf{6}$ 在支链含有优良的空穴传 输基团(三苯胺和咔唑), 同时链端又含有电子传输基团 三氮唑，该聚合物由于同时具备电子和空穴传输能力, 被用来制作深蓝色单层发光器件, 其外量子效率为 $7.28 \%$, 是迄今为止文献报道最高的深蓝色聚合物发光 二极管.

\subsection{2 红光材料}

Deng 等 ${ }^{[21]}$ 在钯催化条件下, 通过 Suzuki 偶联反应 合成了主链含有啞唑单元, 支链含铱配合物的聚合物 7,

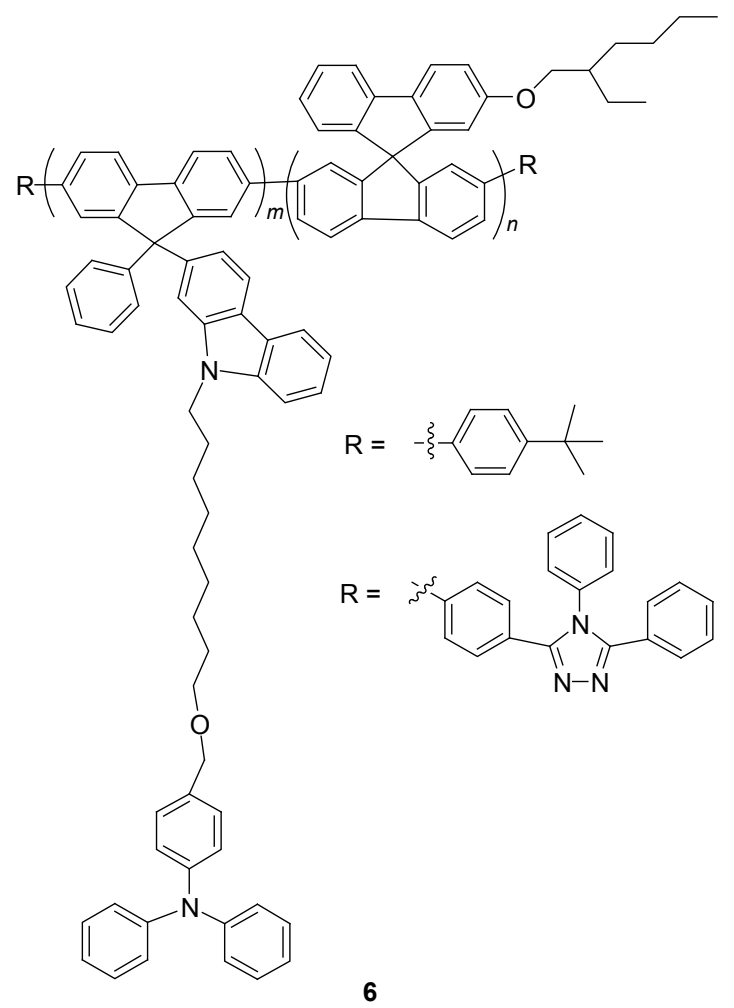

以聚合物 7 为材料制作高分子发光二极管(PLED)器件 时发出的最大红光发射波长为 $628 \sim 634 \mathrm{~nm}$, 其中铱配 合物含量为 $3 \%$ 的发光度最高为 $1125 \mathrm{~cd} / \mathrm{m}^{2}$. 在铱支链 结构的影响下，该配合物的电流效率达到 $1.2 \mathrm{~cd} / \mathrm{A}$, 这 说明了噁唑类结构能有效影响磷光化合物的发光性能, 并很好的应用在有机发光二极管(OLED)器件中.

Kaya 等 ${ }^{[22]}$ 合成了一种高水溶性和半导体的含芴铬 金属螯合物 $8 \mathbf{b}$ (Scheme 1), 为了获得较高的稳定性他们 引入了铬金属原子. 同时, 芴结构的存在促进了聚合物 的配合程度并提高了其苂光性能. 紫外光谱和凝胶渗透 色谱(GPC)检测发现该聚合物有明显的红移现象. $8 \mathbf{b}$ 的 苂光光谱和它在一系列质子与非质子溶剂的高溶解性, 表明该聚合物是一种具有良好的可加工性的红光发光 材料, 对于新型红光发光二级管的研究与开发有很大的 意义.

\subsection{3 绿光材料}

为了尝试不经过共聚芴酮或引入其他低能隙基团 的方法直接实现聚芴的绿光发射, Xiao 等 ${ }^{[23]}$ 在 9 位用烯 丙基取代后再进行聚合的方法(Eq. 2), 得到了聚合物 9b, 并对其发光性质进行了研究. 该聚芴材料在溶液中 的发光峰位于 $403 \mathrm{~nm}$, 处于深蓝光区域. 其固体薄膜的 荧光峰红移至 $456 \mathrm{~nm}$, 其原因在于烯丙基的存在会增 加聚合物链之间的聚集，从而使得光谱红移并展宽. 其 电致发光光谱红移至绿光区域(532 $\mathrm{nm}$ ), 得到了聚合物 绿光单峰发射. 


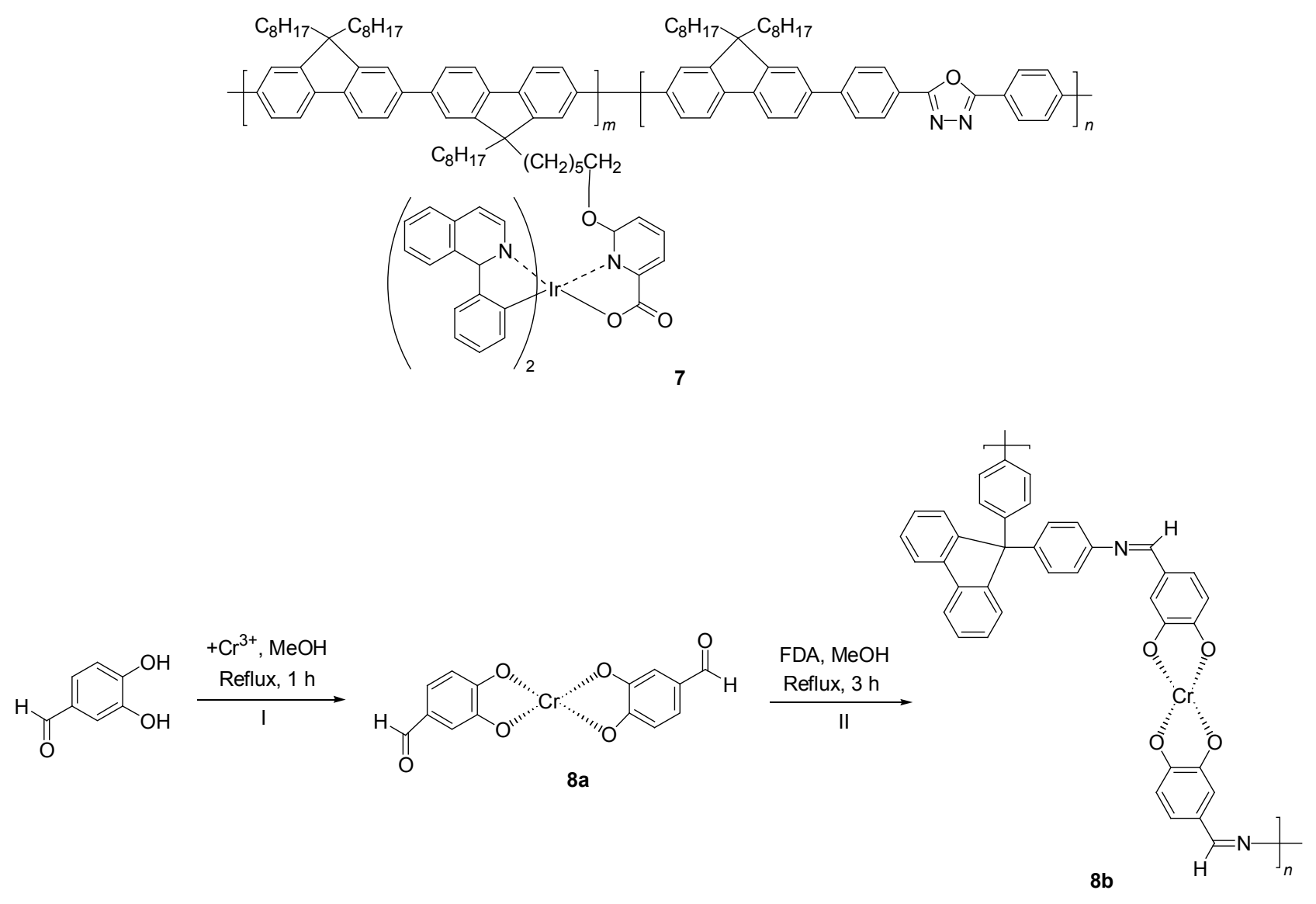

Scheme 1

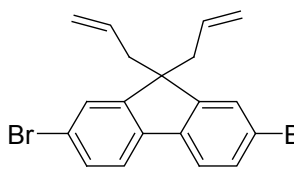

9a
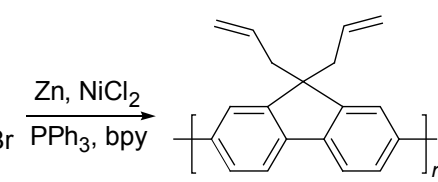

$9 b$

\section{1 .4 白光材料}

白光聚合物电致发光材料 ${ }^{[25]}$ 也是近年来研究的热

2011 年, Wang 等 ${ }^{[24]}$ 通过 Suzuki 偶联反应, 对芴在 2,7 位取代合成共轭聚合物 $\mathbf{1 0}$, 其中三苯胺基团的存在 能降低聚合物的 HOMO 和 LUMO 能级. 苯并噻二唑结 构的引入能有效地防止聚合物的集聚，利用聚合物 $\mathbf{1 0}$ 作为绿光材料制 OLED 器件, 其电致发光效率高达 2.60 $\mathrm{cd} / \mathrm{A}$, 说明器件中注入了高效的平衡载流子.
点之一，其电致发光器件因其潜在的应用吸引了广大科 研者的关注. 从 OLED 加滤光片实现的全彩色显示, 最 理想的白光发射应包括三基色(红、绿、蓝) 中的三色或 者是互补的蓝光与黄光, 且发射光谱要覆盖全部可见光 波长范围( $400 \sim 700 \mathrm{~nm})$, 但是从单一聚合物获得包括 三基色的白光发射，这是相当困难的.目前，从单一的 OLED 获得覆盖全部可见光范围的白光发射的方法主要 有以下两种体系：单一高分子体系和高分子共混体 系 ${ }^{[26]}$.

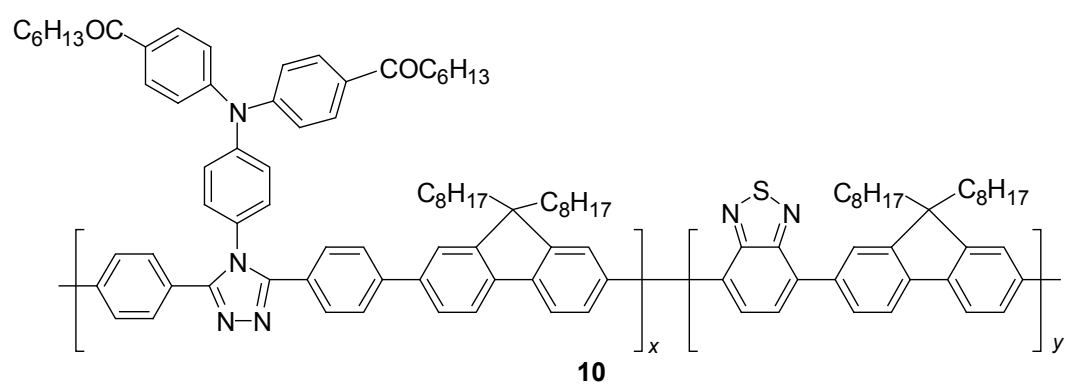


鉴于不同组分发光波长、发光效率和键合式是影响 单一高分子白光发射性能的主要因素, Wang 等 ${ }^{[27]}$ 分别 考察了蓝光和橙光组分发光波长及发光效率和主链连 接与侧链连接方式对白光效率和色纯度的影响规律. 例 如 11a 的一个缺点就是色较差, 其色坐标 $(0.30,0.40)$, 位于白光区但不是纯正的白光, 其原因在于 $11 \mathrm{a}$ 中蓝光 部分和橙光部分的发光波长不匹配. 通过对橙光荎酰亚 胺单元的化学结构进行修饰, 将萗酰亚胺单元的最大发 光波长从 $540 \mathrm{~nm}$ 红移到 $560 \mathrm{~nm}$, 开发出双色白光高分 子 $11 b^{[28]}$. 橙光单元发光波长的红移使 $11 b$ 中橙光部分 和蓝光部分的发光峰位很匹配, 大大地提高了色纯度. $11 \mathbf{b}$ 发射纯正的白光, 色坐标 $(0.35,0.36)$, 非常接近于标 准白光的 $(0.33,0.33)$. 基于该高分子的单层器件电流效 率 $3.8 \mathrm{~cd} / \mathrm{A}$, 外量子效率 $1.5 \%$. 值得强调指出的是, 当 器件的驱动电压从 $8 \mathrm{~V}$ 提高到 $14 \mathrm{~V}$ 时, 器件的电致发光
光谱保持不变，而在同样器件条件下，基于共混物(聚 芴和荎酰亚胺模型化合物)的器件电致发光光谱表现出 明显的电压依赖性，揭示出单一高分子发射白光的优点 和特色.

对于共混高分子体系, 2009 年, Zhang 等 ${ }^{[29]}$ 利用红 光共聚物 12b 和绿光共聚物 12a 共混, 通过调节共混比 例使 $12 \mathrm{a}$ 链到 $12 \mathrm{~b}$ 链间发生不完全能量转移来实现共混 膜的绿光发射. 用 $m(\mathbf{1 2 b}): m(\mathbf{1 2 a})=0.3: 99.7$ 的比例 共混膜作 $\mathrm{InGaN}$ 基蓝光芯片的苂光下转换材料能实现 有效的白光发射. 这种杂合白光器件在 $20 \mathrm{~mA}$ 电流驱动 下相关色坐标为 $(0.34,0.32)$ 、色温为 $6798 \mathrm{~K}$ 、色散指数 为 85 .

2011 年, Moon 等 $^{[30]}$ 合成了一种含芴结构的新型白 光聚合物 $13 \mathrm{~b}$, 用 13a 聚合物制作发光器件测得其发光

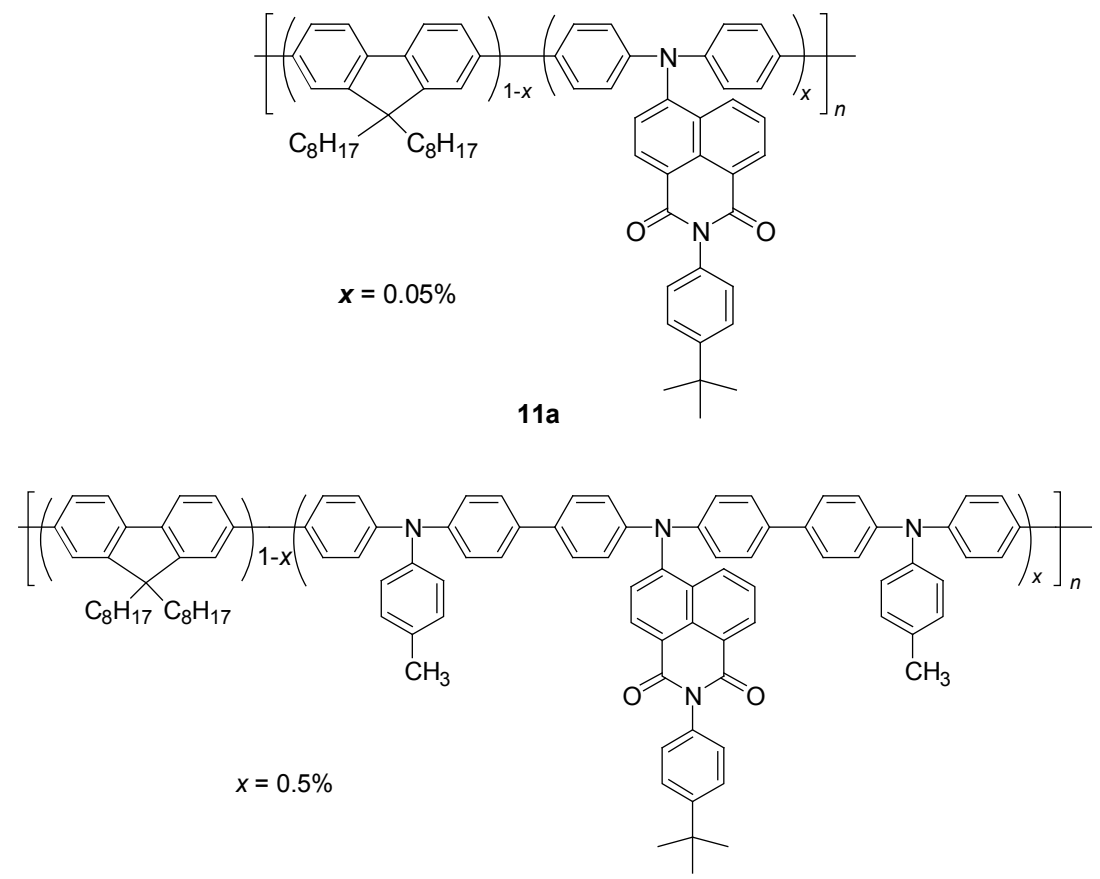

$11 b$

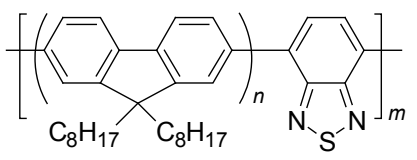

$12 a$

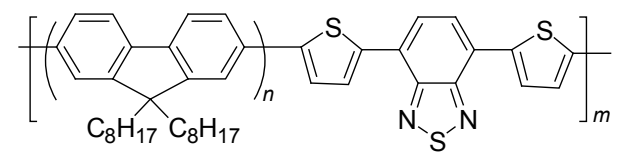

$12 b$

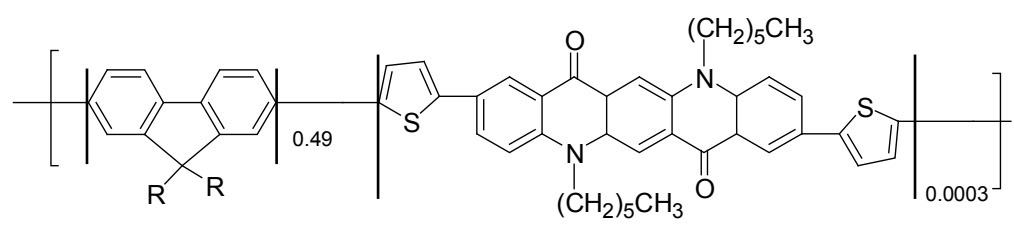

$13 a$ 


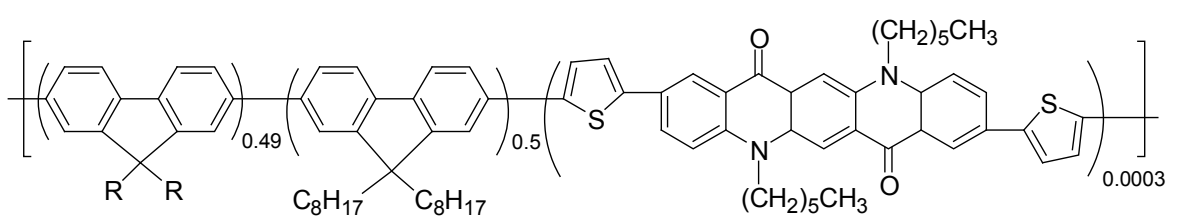

$13 b$

效率为 $0.50 \mathrm{~cd} / \mathrm{A}$, 其电源效率为 $0.24 \mathrm{~lm} / \mathrm{W}$, 最大亮度 值为 $1450 \mathrm{~cd} / \mathrm{m}^{2}$, 通过测试发现相对于聚合物 13a, 聚 合物 13b 的性能更好, 其发光效率、电源效率、最大亮 度分别为 $0.71 \mathrm{~cd} / \mathrm{A}, 0.34 \mathrm{~m} / \mathrm{W}, 3905 \mathrm{~cd} / \mathrm{m}^{2}$, CIE(国际照 明委员会 $)$ 坐标为 $(0.31,0.35)$ 很接近标准白光, 是较理想 的白光材料.

2007 年, Hsieh 等 ${ }^{[31]}$ 将发射橙红色磷光的铱配合物 引入聚荡的侧链中得到单线态/三线态混合型双色白光 高分子 14, 这也是发展高效双色白光高分子的有效途 径之一. 当铱配合物含量达到 $0.3 \%$ 时, 器件色坐标 $(0.33,0.32)$, 其发光效率可达到 $3.2 \mathrm{~cd} / \mathrm{A}$.

\subsection{5 黄光材料}

为了确保发光器件的性能良好, 必须保证电荷注入 和传输平衡. 器件的发光效率低主要是由两极的电子、 空穴注入及传输不平衡引起的. 平衡电子、空穴注入和
传输的一个有效策略是通过化学合成, 将具有电子传输 性能和空穴传输性能的部分键合为一体 ${ }^{[32]}$, 这样可以 将同时具有电子传输和空穴传输双重功能的材料组装 成单层发光器件. 单层发光器件制作方便, 发光颜色稳 定，在实际应用方面，简化了工艺，降低了成本，具有 广阔的商业化前景. 8-羟基喹啉金属配合物及其衍生物 具有很好的热稳定性和发光亮度, 是优良的电子传输材 料. 曾和平研究小组 ${ }^{[33,34]}$ 利用苆、三苯胺、咔唑等具有 良好空穴传输性能的大共轭取代基修饰 8-看基喹啉的 结构或者改变其配位金属原子(主要是对 8-羊基喹啉环 上的 2, 5 位或是 7 位进行结构修饰)(Scheme 2), 结果表 明: 芴类等单元的引入可以改变 HUMO 与 LOMO 之间 的能隙差，从而改变发光波长，并利用金属配合物 15a 15d 制作了发黄光的单层发光器件.

14
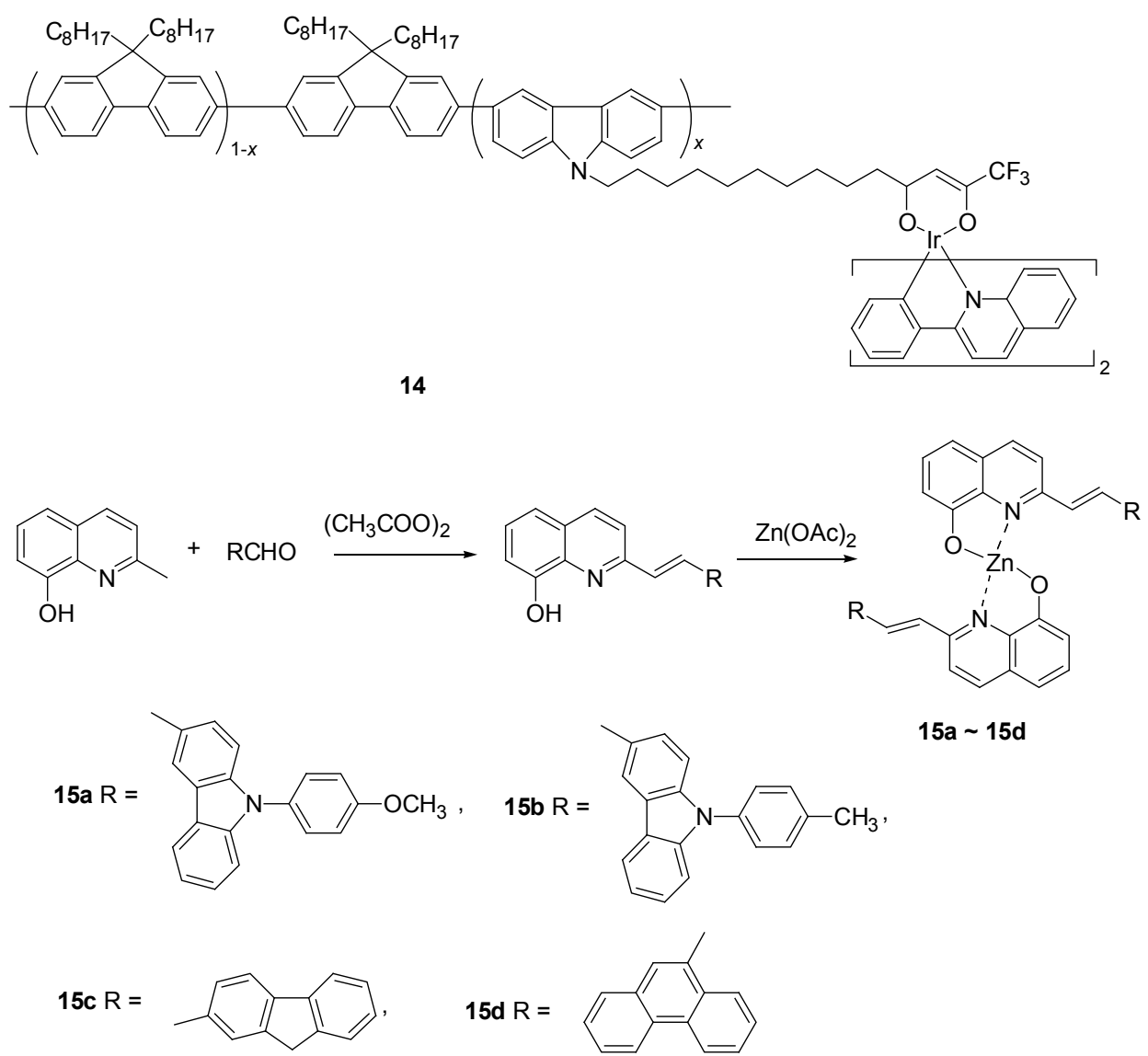

Scheme 2 
Yuen 等 ${ }^{[35]}$ 设计合成了含有荡单元的 6 种不同系列 (C-N-N)型铂配合物(Scheme 3), 对其光物理性质和电致 发光特性进行了研究. 结果显示: 该类配合物在有机溶 剂中具有良好的溶解性, 可以通过湿方加工制备 OLED 器件. 发射光谱位于 $558 \sim 601 \mathrm{~nm}$ 之间, 主要是由于受 激发的分子内和金属到配体电荷转移(MLCT)的三重态 引起, 最大量子效率为 0.76 . 其中由系列 $\mathbf{3}$ 的配合物 $\mathbf{3 d}$ 制得的黄光 OLED 器件: 其发光效率和最大亮度分别 为 $14.7 \mathrm{~cd} / \mathrm{A}, 27000 \mathrm{~cd} / \mathrm{m}^{2}$.

\section{2 光致变色材料}

20 世纪 90 年代, 出现了一种新型的有机光电材 料一一有机光致变色材料. 由于其在高密度数据存储、 全息图像加工和光放大等许多领域具有潜在的应用前 景, 因此, 在短短的十几年中, 取得了巨大进展. 在众 多的有机光折变材料中, 芴类材料由于其优异的性能而
越来越受到重视，成为人们研究的重点之一[36 38]

\subsection{1 新型二芳基乙烯光致变色化合物}

对于有机小分子而言，二芳基乙烯(DTE)具有优良 的热稳定性、灵敏的响应性、耐久的抗疲劳性，被广泛 认为是最具有前途的光致变色化合物, 也是最有可能实 用化的光致变色材料. 2011 年，曾和平等 ${ }^{[39]}$ 设计合成了 一种新型二芳基乙烯光致变色分子 16. 由于螺二茀具 有正交三维空间结构，可以避免分子中发色团的紧密堆 积，从而减少聚集体或激基缔合物的形成，提高材料的 光学稳定性, 改善材料的热稳定性, 降低分子结晶的趋 势，得到比较稳定的无定型材料. 用螺二芴修饰二芳基 乙烯(DTE), 并且用低芳香稳定化能的呋喃代替传统的 高芳香性的噻吩环, 发现其具有良好的光致变色性能, 且稳定性好 ${ }^{[40]}$. 合成的化合物在紫外光的照射下会发 生关环反应(Eq. 3)得到新的结构 17.

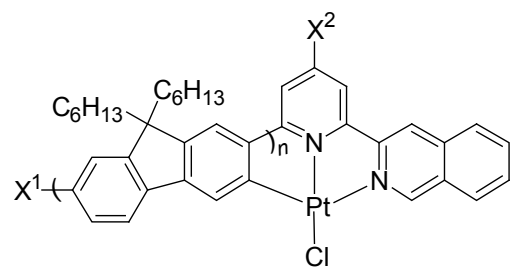

系列 3

$X^{1}=H, X^{2}=H ; X^{1}=H, X^{2}=P h ; X^{1}=B r, X^{2}=P h ; X^{1}=H, X^{2}=3,5-(t-B u)_{2} C_{6} H_{3}$;

系列 1

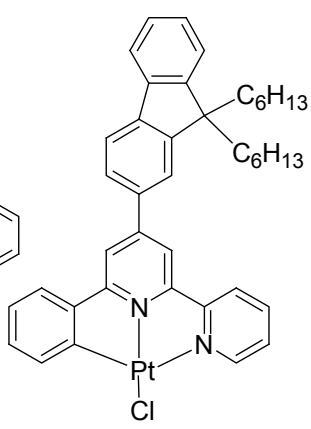

系列 2<smiles>[X][X]c1ccc2cc3ccccc3c(C)c2c1</smiles>

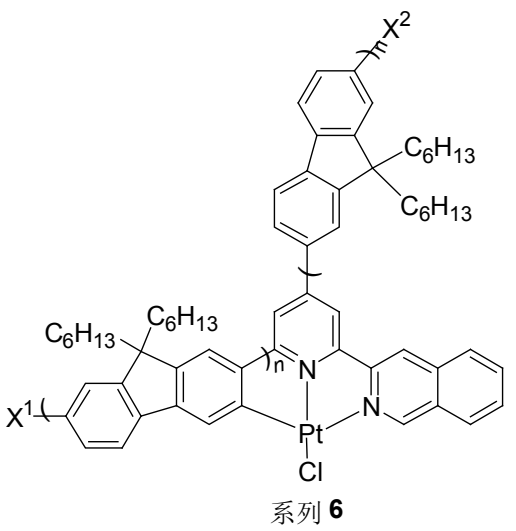

$$
\begin{aligned}
& n=1 ; \mathrm{X}^{1}, \mathrm{X}^{2}=\mathrm{H} \\
& n=1 ; \mathrm{X}^{1}, \mathrm{X}^{2}=\mathrm{Br} \\
& n=2 ; \mathrm{X}^{1}, \mathrm{X}^{2}=\mathrm{H}
\end{aligned}
$$

Scheme 3 

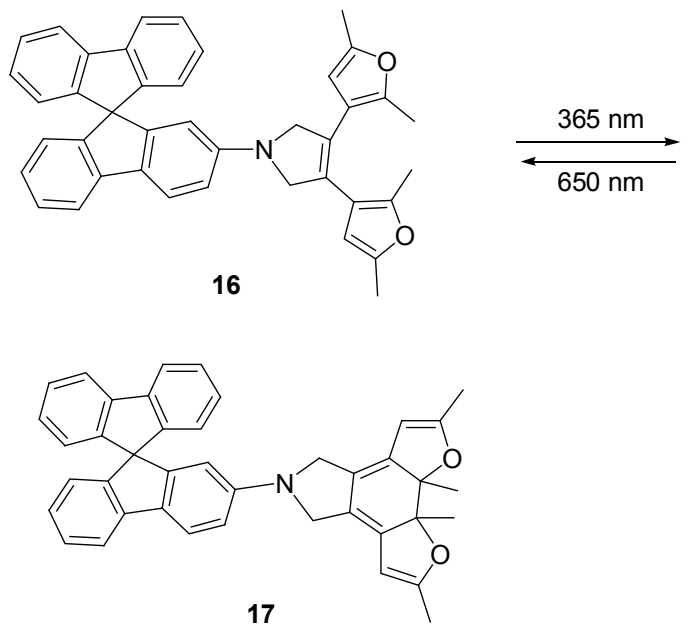

\section{2 .2 二氢喹啉酮类光致变色化合物}

2,5-二芳基-1,3,4-噁二唑(OXD)衍生物具有良好的 热稳定性、化学稳定性以及高的光致发光量子收益率, 因而受到广泛关注. Dürr 等 ${ }^{[41]}$ 合成研究的 dihydroindolizines (DHIs) 和 dihydro 5-azaindolizines (DHAIs) 是有 名的光致变色材料, 也被认为是末来存储设备和电子设 备最有前景的替代品, 这两种材料都是基于电环化却有 着截然不同的形式: 开环式和闭环式. 在这个基础上, 2010 年, Ahmed 等 ${ }^{[37]}$ 在钯催化条件下通过交叉偶联反应 在 OXD 结构上添加芴骨架，合成了化合物 18a, 该化合 物在紫外光的照射下回变成开环式的化合物 $18 \mathrm{~b}(\mathrm{Eq}$. 4), 其发光性能也有了很大的改变.
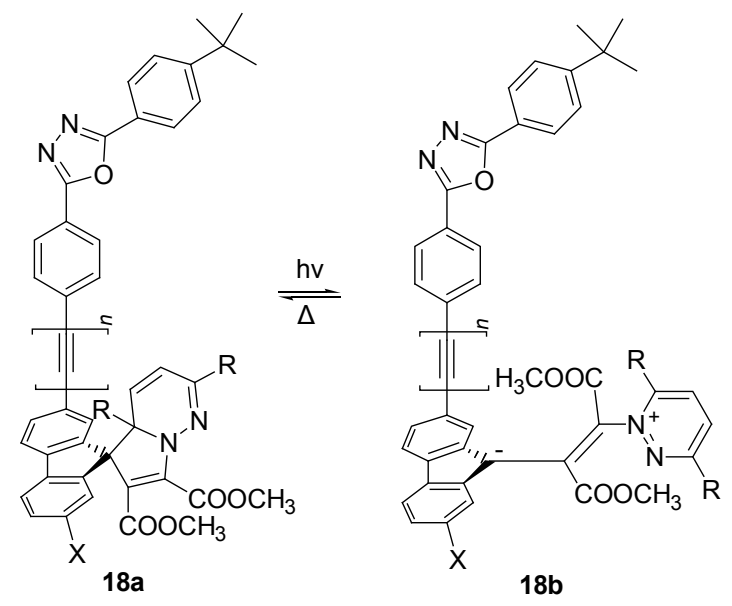

\section{3 双光子吸收材料}

相对于传统的单光子吸收(one-photon absorption, 1PA), 双光子吸收(two-photon absorption, 2PA) 在很多领

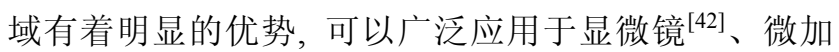
工 $^{[43]}$ 、三维数据存储 ${ }^{[44]}$ 、光动力学治疗 ${ }^{[45]}$ 、光限幅 ${ }^{[46]}$ 和生物活性物种的局部释放 ${ }^{[47]}$, 因而吸引了研究人员 的极大兴趣. 芴类衍生物因具有较大的电子离域、高的
苂光量子产率和好的光热稳定性，成为一类备受关注的 双光子吸收材料. 研究表明: 以芴环为共扼骨架，并且 在骨架两端连接强的电子受体一给体 $(A-\pi-D)$ 或强的给 体一给体 $(D-\pi-D)$ 或强的受体一受体 $(A-\pi-A)$ 的有机分 子, 在强的激光脉冲作用下会发生双光子吸收. 因此, 芴环作为一类优秀的非线性生色团，通过改变电子给体 的给电子能力或受体的吸电子能力和共扼链的长度, 已 经被设计出一系列具有大的双光子吸收截面和强的双 光子上转换荧光的有机双光子吸收材料 ${ }^{[48 ~ 52]}$.

2010 年, Moura 等 ${ }^{[52]}$ 通过量化计算的方法系统研究 了含有不同芳香取代基的 161 个芴类衍生物的双光子吸 收性能，芳香取代基包括苯环、五元和六元杂环，以及 苯并五元和六元杂环. 研究结果显示: 供电子基团取代 的分子双光子性能要优于吸电子基团取代的分子，而且 其共轭程度越大, 双光子吸收截面也越大. 其中理论值 最大的是分子 19a 和 19b, 吸收截面分别为 3408 和 3138 GM. 该研究为如何设计性能优异的双光子吸收材料提 供了理论指导.

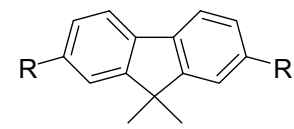

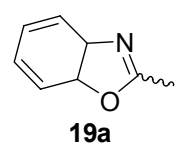

$19 \mathrm{a}$

$\lambda_{1 \mathrm{pa}}=362 \mathrm{~nm}$ $\lambda_{2 \mathrm{pa}}=503 \mathrm{~nm}$ $\delta_{\max }=3408 \mathrm{GM}$

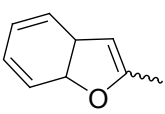

$19 b$

$\lambda_{1 \mathrm{pa}}=366 \mathrm{~nm}$

$\lambda_{2 \mathrm{pa}}=503 \mathrm{~nm}$

$\delta_{\max }=3138 \mathrm{GM}$
2010 年, Belfield 等 ${ }^{[53]}$ 报道了以芴为核的两个 D- $\pi-A$ 和两个 $\mathrm{A}-\pi-\mathrm{A}$ 的芴类衍生物 $\mathbf{2 0 a} \sim \mathbf{2 0 d}$ ，该类化合物具有 高的荧光量子产率 $(0.86 \sim 0.98)$ 和大的双光子吸收截面 (220 1060 GM). 其中噻吩环和烷基链的引入会有助于 增大双光子吸收截面. 进一步用于双光子荧光显微成像 研究显示：化合物 20a 可以有效地富集在细胞质中且具 有低的细胞毒性的.

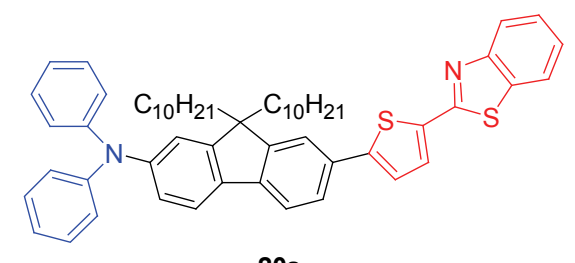

$20 a$

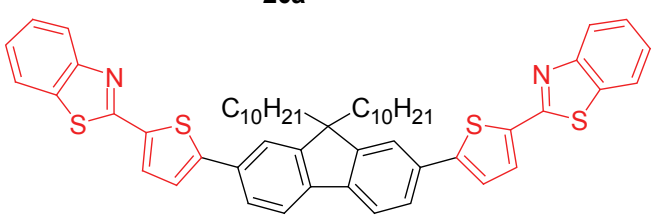

$20 b$ 


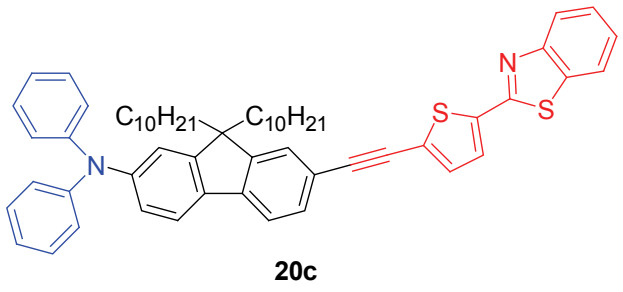

20c

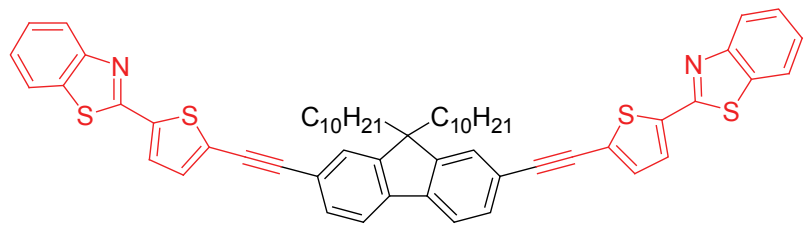

20d

Qin 等 ${ }^{[54]}$ 通过 Suzuki 反应设计合成了含芴, 三苯胺 给体单元和二氰基吡啶受体单元的聚合物 21, 该聚合 物在有机溶剂中具有良好的溶解性和热稳定性. 利用双 光子激发荧光光谱研究了溶剂效应和浓度对其双光子 吸收性能的影响, 研究表明: 在 $940 \mathrm{~nm}$ 激光的激发下, 在中等极性的二氯甲烷溶剂中其具有最大的吸收截面 $13260 \mathrm{GM}$. 而在氯仿溶剂中, 其吸收截面会随着聚合 物的浓度增大而减少, 表明在该溶剂中其双光子吸收过 程并不是单纯的链内过程.

Huo 等 ${ }^{[5]}$ 利用皮秒激光光源分别研究了含 3 个 (22a), 5 个(22b)和 7 个(22c)荡单元的三种寡聚芴非线性 光学性能: 包括三光子吸收、双光子吸收和激发态吸收, 研究结果显示: 随着芴类单元的增多, 三光子吸收转为 双光子吸收, 其中 $22 \mathrm{a}$ 三光子吸收横截面值为 $1.36 \times$
$10^{-76} \mathrm{~cm}^{6} \cdot \mathrm{s}^{2} .22 \mathrm{~b}$ 和 $22 \mathrm{c}$ 的双光子吸收横截面值分别为 1230 和 $1780 \mathrm{GM}$.

\section{4 在太阳能电池上的应用}

聚芴及其衍生物是一类优异的电致发光材料, 具有 较高的热和化学稳定性, 及较好的成膜性. 通常情况下, 聚荡具有较大的能带隙 $(3.68 \mathrm{eV})$, 被广泛用于发光二极 管 (OLED) 的蓝光材料 ${ }^{[56]}$. 然而大的能带隙在作为光伏 材料应用方面是非常不利的. 所以一般芴的均聚物很少 直接用在有机太阳能电池领域 ${ }^{[57,58]}$.

\subsection{1 芴类窄带隙聚合物}

2003 年, Svensson 等 ${ }^{[3]}$ 首先报道了荡与二噻吩苯并 噻二唑 23a 的共聚物 23b, 它的设计思路开启了聚茀光 伏材料设计的一个新的起点. 通过选择与窄带隙的单体 二噻吩苯并噻二唑共聚, 使吸收波长红移, 拓宽了吸收 带宽, 使其吸收覆盖整个可见光区域. 基于 $23 \mathrm{~b} / \mathrm{PCBM}$ 的初步光伏器件结果为: $\mathrm{VOC}=1.04 \mathrm{~V}, \mathrm{JSC}=4.66$ $\mathrm{mA} / \mathrm{cm}^{2}, \mathrm{FF}=0.46, \mathrm{PCE}=2.2 \%$. 高效率获得的原因在 于聚合物宽的吸收和高的迁移率.

Liu 研究组 ${ }^{[59,60]}$ 合成了以芴为基础与苯并噻二唑并 喹喔啉单元共聚的系列共聚物 24a, 24b, 24c. 24a 的 HOMO 和 LUMO 能级分别是 $-5.6,-3.6 \mathrm{eV}$. 带隙是 $2.0 \mathrm{eV}$, 光谱响应范围 300 $850 \mathrm{~nm}$. 基于 $24 \mathrm{a} / \mathrm{PCBM}$ $(1: 6)$ 的本体异质结光伏器件在模拟太阳光照下, $\mathrm{VOC}=0.78 \mathrm{~V}, \mathrm{JSC}=3.0 \mathrm{~mA} / \mathrm{cm}^{2}, \mathrm{PCE}=0.96 \%$.<smiles>Cc1nc(/C=C/c2ccc(N(c3ccccc3)c3ccc(Br)cc3)cc2)c(C#N)c(/C=C/c2ccc(N(c3ccccc3)c3ccc(Br)cc3)cc2)c1C#N</smiles>

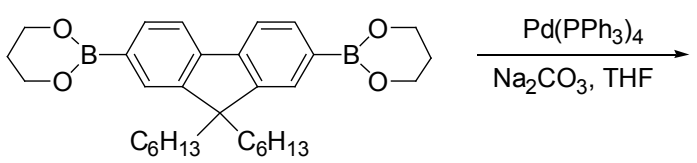<smiles></smiles>

21

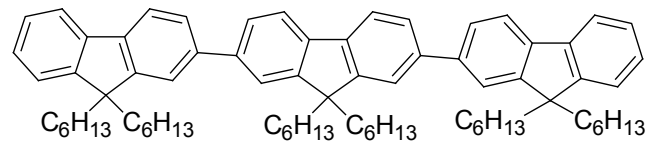

22a 


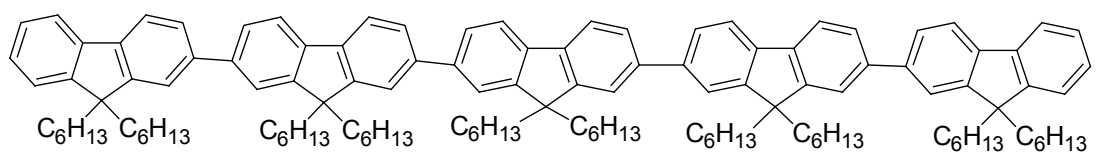

22b

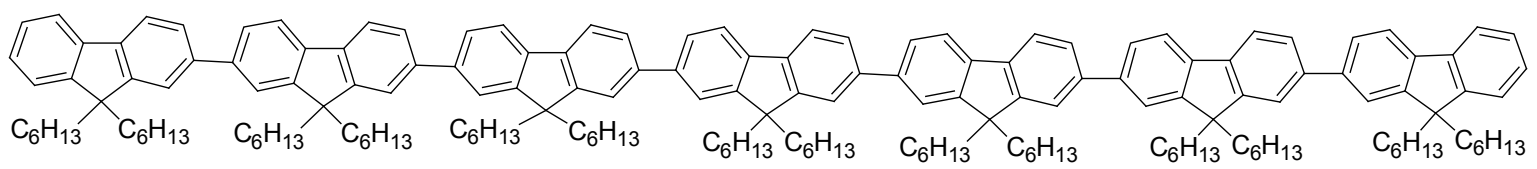

22c

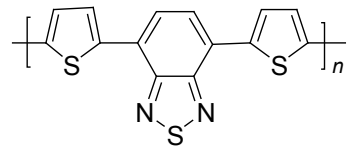

23a

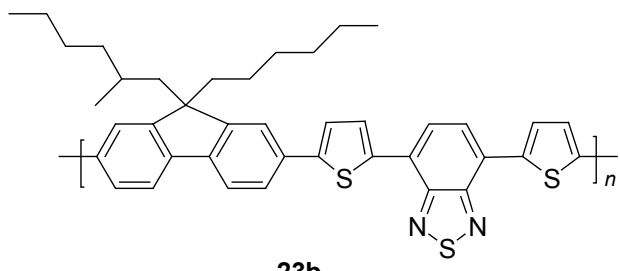

$23 b$

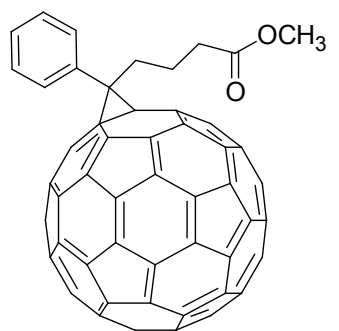

PCBM

以 $24 \mathrm{a}$ 为基础, 在苯环上连接上烷氧基以后, 得到 了 $24 b^{[61]}$. 基于 $24 b / P C B M ~(1: 3)$ 的本体异质结光伏器 件在 $100 \mathrm{~mW} / \mathrm{cm}^{2}$ 光照下, 最佳的器件结果为 $\mathrm{VOC}=$ $0.59 \mathrm{~V}, \mathrm{JSC}=8.88 \mathrm{~mA} / \mathrm{cm}^{2}, \mathrm{FF}=0.42, \mathrm{PCE}=2.2 \%$. 烷氧 基的引入，不仅提高了聚合物的溶解性和平均分子量, 而且可以调控 HOMO/LUMO 能级. $24 \mathbf{b}$ 具有更高的
HOMO 和 LUMO 能级: 分别是 $-5.0,-3.4 \mathrm{eV}$. 这样使 得它的 Ed 值更大，更有利于电子从 $24 \mathrm{~b}$ 的 LUMO 轨道 跃迁到 PCBM 的 LUMO 轨道上. 24b 更窄的带隙 $1.6 \mathrm{eV}$, 也从它的光谱响应范围 500 $800 \mathrm{~nm}$ 得到了验证.

研究发现在 24c 与 PCBM 的混合膜中，并没有观测 到苂光猝灭现象(图 1), 表明苯并噻二唑并喹喔啉单体 具有很强的接受电子能力, 它与芴的共聚, 使得 $24 \mathrm{c}$ 的 具有更低的 LUMO 轨道能量, 实验值为 $-4.0 \mathrm{eV}$, 比 PCBM 的报道值 $-3.8 \mathrm{eV}$ 还要低. 禁阻了电子向 PCBM 的跃迁. 然而当 $24 \mathrm{c}$ 和 BTPF [3'-(3,5-bis-trifluoromethyl-phenyl)-10-(4-nitrophenyl)pyrazolino[70]fullerene]混合 时，可以观测到部分的荧光猝灭，表明它们之间发生了 电子转移. 原因是 BTPF 具有更低的 LUMO 能量: -4.1 $\mathrm{eV}$. 促进了给体 $\mathbf{2 4 c}$ 与 BTPF 之间的电子转移. 基于 $\mathbf{2 4 c}$ / BTPF (1:4)的本体异质结光伏器件. 在模拟太阳光照 下, $\mathrm{VOC}=0.58 \mathrm{~V}, \mathrm{JSC}=3.4 \mathrm{~mA} / \mathrm{cm}^{2}, \mathrm{FF}=0.54, \mathrm{PCE}=$ $0.7 \%$.

\subsection{2 芴类含磷光金属配合物的聚合物}

当前聚合物/富勒烯太阳能电池效率低的重要原因 之一是聚合物活化层太薄. 而增加活化层的厚度可提高 光子吸收效率，但这又与激子需要较小的扩散长度相矛 盾. 所以提高激子的扩散长度就显得意义重大. 激子的 扩散长度，依赖于它的迁移率和寿命. 而三线态的激子 比单线态激子具有更长的寿命. 所以含有磷光金属配合 物的聚合物是潜在的高效聚合物太阳能电池材料.
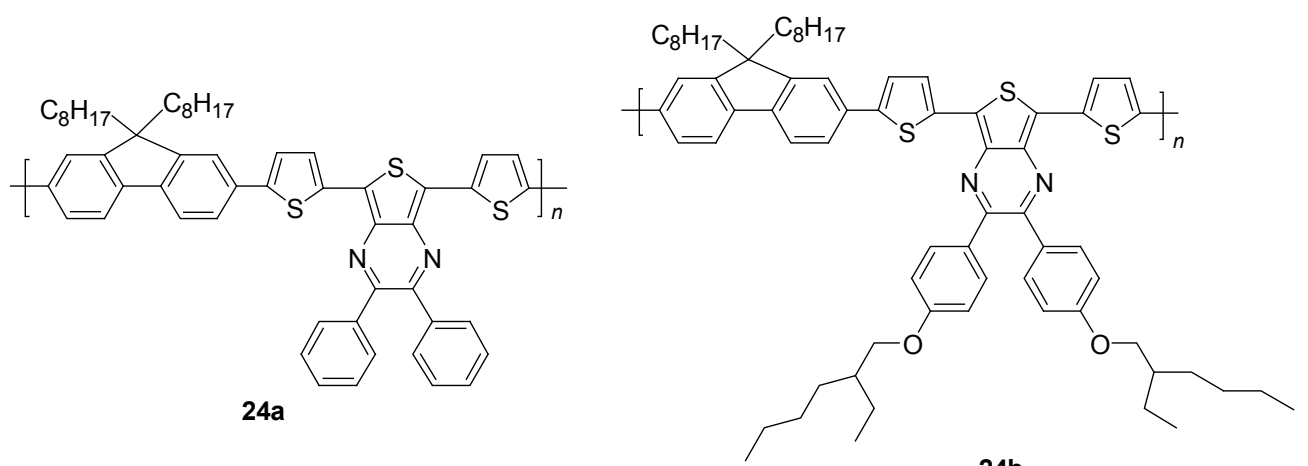

24b 

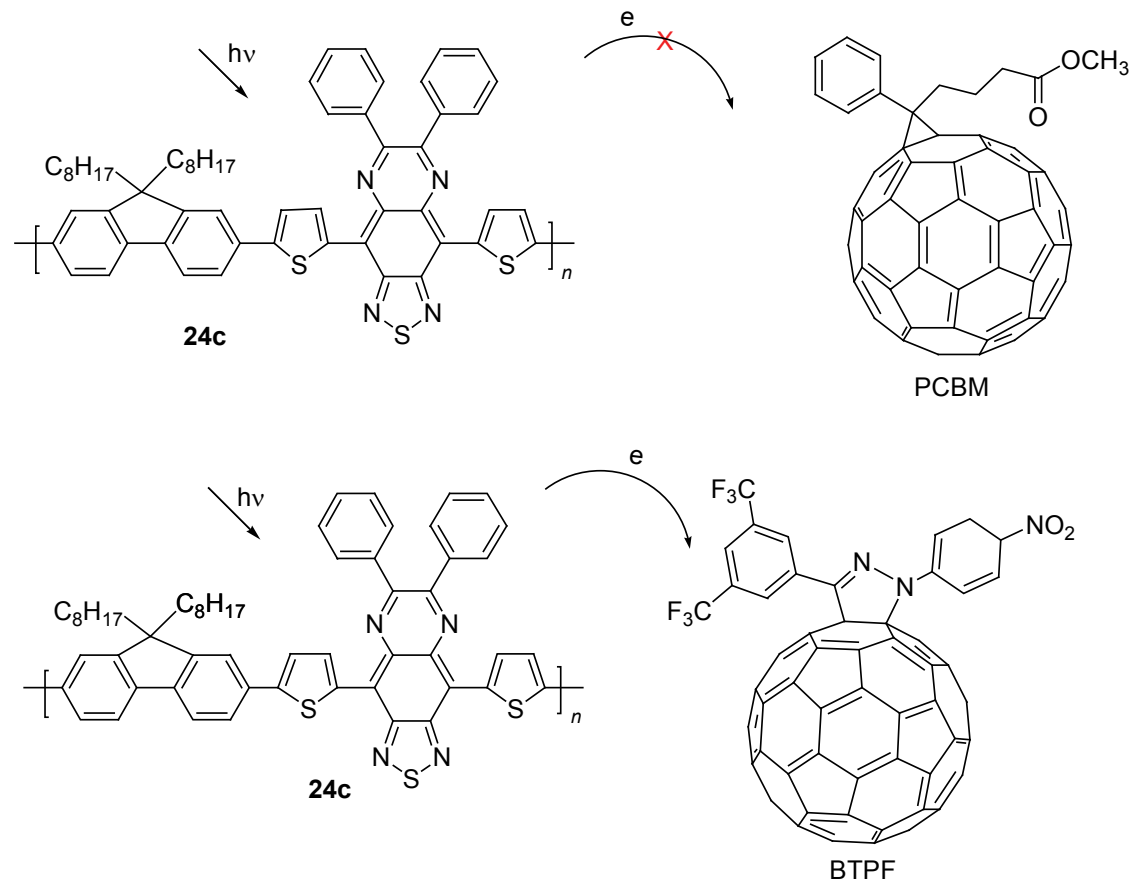

图 1 聚合物 $24 \mathrm{c}$ 和 $\mathrm{PCBM}$ 以及 BTPF 的分子间电子转移示意图

Figure 1 Illustration of electron transfer between polymer $24 \mathbf{c}$ and PCBM or BTPF

Hou 等 ${ }^{[2]}$ 用 Suzuki 偶合反应合成了主链含 Pt 的卟 啉配合物的红色电致发磷光聚合物 25 , 实验证明 $\mathrm{Pt}$ 被 成功地插入到聚合物的主链中. 苂光光谱的衰退现象说 明这些聚合物的发射是三线态发射. 当聚合物中 Pt-TPP 含量为 $0.5 \%$ 时, 芴链段的苂光发射即被完全淬灭了. 其 中基于 25 (Pt-TPP 含量为 $1 \mathrm{~mol} \%$ ) 的器件的量子效率最 高, 在 $676 \mathrm{~nm}$ 处为 $0.43 \%$. 利用这种化合物制备的光伏 器件的能量转换效率较低可能由分子中各功能组分的 配比及匹配问题导致的. 尽管该化合物的合成路线非常 复杂, 效率较低, 但它能有效的避免在异质结太阳能电 池中各组分间的相分离, 为以后的研究拓宽了思路.

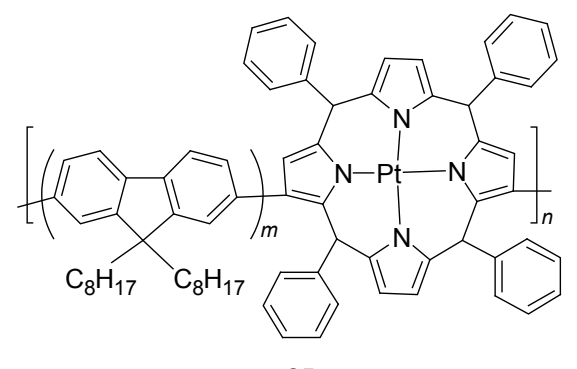

25

2008 年, Holdcroft 等 ${ }^{[3]}$ 利用 Suzuki 反应, 设计合成 了支链含有铱配合物, 主链由荡单元与苯联吡啶单元共 聚的聚合物 26a, 同时与不含铱配合物的聚合物 26b 进 行了对比研究: 发现经过激发以后, 26b 的荧光发射光 谱的峰值在 $422 \mathrm{~nm}$. 而 $26 \mathrm{a}$ 的磷光发射光谱峰值在 596 $\mathrm{nm}$, 磷光三线态的寿命为 $0.26 \mu \mathrm{s}$. 当 $\mathbf{2 6 a}$ 与 $\mathrm{PCBM}$ 共混 时, 它的磷光被完全猝灭. 表明聚合物的三线态激子与 PCBM 之间发生了有效的电子转移. 26a, 26b 与 PCBM 共混(重量比 $1: 4$ )的电池效率分别为: $0.07 \%, 0.002 \%$. 结果证实了长寿命的三线态激子有利于提高光电转换 效率.

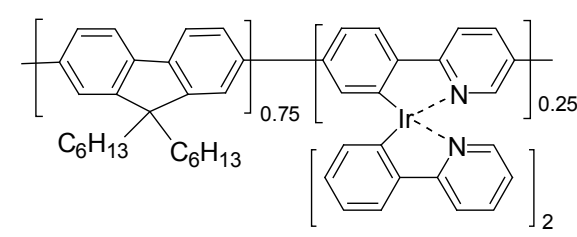

$26 a$

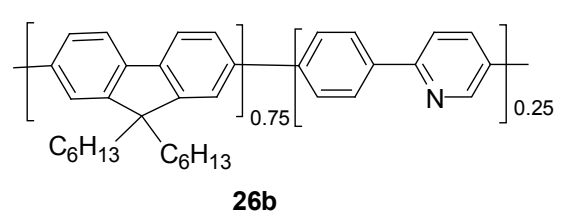

Liu 等 ${ }^{[64]}$ 合成了一系列含噻吩基和重原子铂的聚芴 衍生物 $27 \mathbf{a} \sim 27 \mathbf{d}$, 该类聚合物可溶, 在可见光区域有吸 收. 将其与 PCBM 制成异质结太阳能电池, 能量转化效 率最高为 $2.9 \%$. 通过研究发现, 光伏性能和聚合物链上 噻吩基的数量有关:增加噻吩基的数量,电池性能加强. 并详细解释了噻吩链长度对提高电池性能和电荷传输 性能的影响. 在共聚物和可溶性富勒烯混合薄膜中, 纳 
米相的可控分离有助于形成载流子传输的连续通道, 从 而提高聚合物光伏器件的光电流.

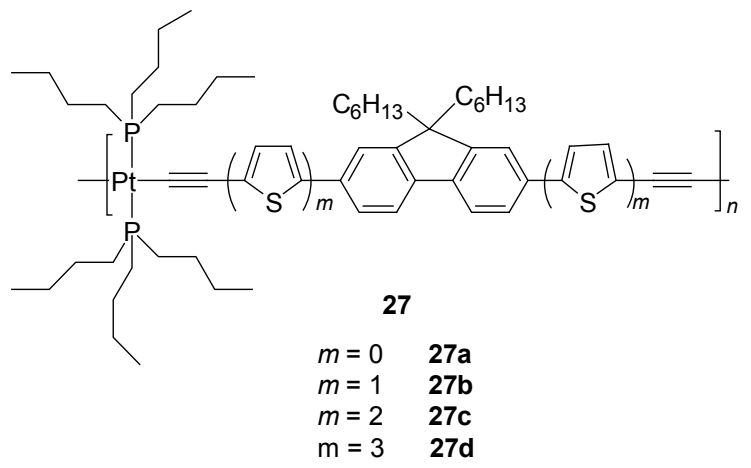

\section{2 在生物医药领域的应用}

\section{1 水溶性聚芴衍生物的生物传感器上的应用}

生物传感器是感知生物体内的各种生理的, 生 化的和病理的信息, 把它们传递出来并转换为易处理的 电信号的装置. 基于共轭聚合物的新型生物传感体系对 于阐明生物体系中的信息传递, 特别是对疾病的早期诊 断方面具有重要的应用前景. 水溶性聚芴衍生物由于具 有很好的化学和热稳定性、高的荧光量子产率以及 $\mathrm{C}^{9}$ 位易于修饰等特性, 近年来在生物传感领域得到了广泛 应用 ${ }^{[65 \sim 69]}$.

水溶性的聚芴衍生物主要是通过在 $\mathrm{C}^{9}$ 位侧链修饰 上亲水的离子基团, 主要有阳离子和阴离子两种. 由于 侧链带有阳离子基团的聚合物能与带有负电荷的 DNA, RNA 和蛋白质等形成静电复合物, 从而实现特异识别, 阳离子水溶性聚芴衍生物被广泛研究. 被广泛应用的阳 离子聚合物主要是含有季铵盐类基团的聚合物. 最早报 道的是 Bazan 小组 ${ }^{[70]}$ 将侧链为二甲胺基的荡单体和苯 二硼酸, 通过 $\mathrm{PdCl}_{2}$-(dppf) 催化在 $\mathrm{THF} / \mathrm{H}_{2} \mathrm{O}$ 溶液中进行 Suzuki 聚合得到了侧链含有二甲胺基的共聚物, 然后 加入碘甲烷将二甲胺基季铵化得到了水溶性聚荡衍生 物 28a. 由于以上合成方法中的带有胺基侧链的芴单体 不易分离纯化, 他们在先前的合成路线上加以改进, 首 先在芴单体的 $\mathrm{C}^{9}$ 位修饰上末端为溴取代的烷基链, 再 以同样的方法合成了阳离子水溶性聚芴衍生物 $28 b$. Wang 等 ${ }^{[71]}$ 利用阳离子水溶性聚荡的苂光放大效应设计 发展了高灵敏度的 $\mathrm{H}_{2} \mathrm{O}_{2}$ 和葡萄糖检测体系. 检测体系 由水溶性聚芴 (28b) 和嗍酸酯保护的苂光素(F1-BB) 组 成. 2007 年, Wang 等 ${ }^{[69]}$ 制备了荧光素标记的 DNA 与阳 离子聚荡 $28 \mathrm{~b}$ 的静电复合物, 通过测定聚茀和荧光素之 间的荧光共振能量转移(FRET)信号, 实现了对限制性 及非限制性核酸内切酶的灵敏检测. 其中核酸酶 S1 的 检测限(LOD) 非常低, 与目前报道的最灵敏的检测方法
处于同一数量级.

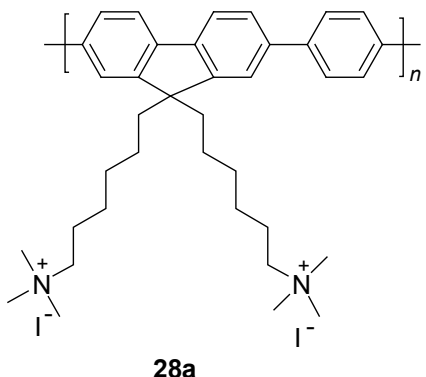

$28 a$

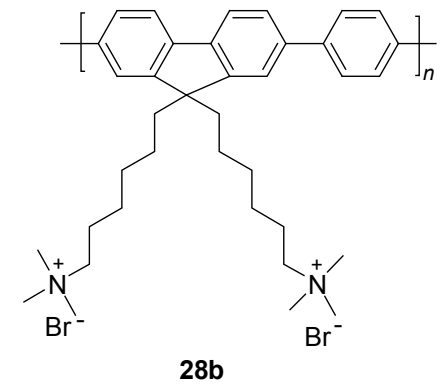

2004 年, Pei 小组 ${ }^{[72]}$ 报道了一种带咪唑功能团的聚 芴在四氢呋喃(THF)溶液中可以实现对 $\mathrm{Cu}$ 的高选择性 检测. 在此基础上, Wang 等 ${ }^{[73]}$ 合成了侧链带咪唑功能团 的阳离子聚芴 $28 \mathrm{c}$, 利用其对 $\mathrm{Cu}^{2+}$ 的络合能力设计了一 种新的检测一氧化氮(NO)的体系(图 2). 该体系由三部 分组成：阳离子聚芴 $\mathbf{2 8 c}$ 、二价铜离子和 $\mathrm{NO} . \mathrm{Cu}^{2+}$ 通过 $\mathrm{NCu}$ 相互作用与聚荡结合, 通过光诱导的电子转移过程 将聚芴的苂光淬灭. 加入 $\mathrm{NO}$ 后, $\mathrm{NO}$ 将顺磁性的 $\mathrm{Cu}^{2+}$ 转变成抗磁性的 $\mathrm{Cu}^{+}, \mathrm{Cu}^{+}$不能有效地淬灭聚荡, 荧光得 到恢复. 该体系具有很高的选择性, 其它几种与生物相 关的氮化合物如 $\mathrm{NOBF}_{4}, \mathrm{NaNO}_{2}$ 和 $\mathrm{NaNO}_{3}$ 都不能使聚芴 的荧光恢复. 这种阳离子聚苆 $/ \mathrm{Cu}^{2+}$ 的体系可作为高灵 敏性和高选择性检测 NO 的平台.

\section{2 芴偶氮基化合物的合成及对植物生长的作用}

根据活性亚结构连接原理, 如将水杨醛、芴环和氨 基硫腿结合到同一分子中，以期获得新的生物活性的化 合物，郡宇 ${ }^{[74]}$ 以荡环为骨架，通过偶氮基与系列水杨 醛 ${ }^{[75]}$ 偶联(Eq. 6)合成了系列芴偶氮基水杨醛缩氨基芳 基硫脲衍生物 29, 用平皿培养法对其进行了植物生长 调节活性测试. 合成化合物与同浓度的吲哚乙酸相比, 在较低浓度下对油菜籽的生长均有促进作用. 当化合物 浓度从 $1 \mathrm{mg} / \mathrm{L}$ 增至 $100 \mathrm{mg} / \mathrm{L}$ 时, 多数化合物表现出高 浓度抑制植物生长低浓度促进植物生长的规律.

\section{3 人工合成的芴类药物}

Atemether-Lumefantrine(商品名为 Coartem)是一种 

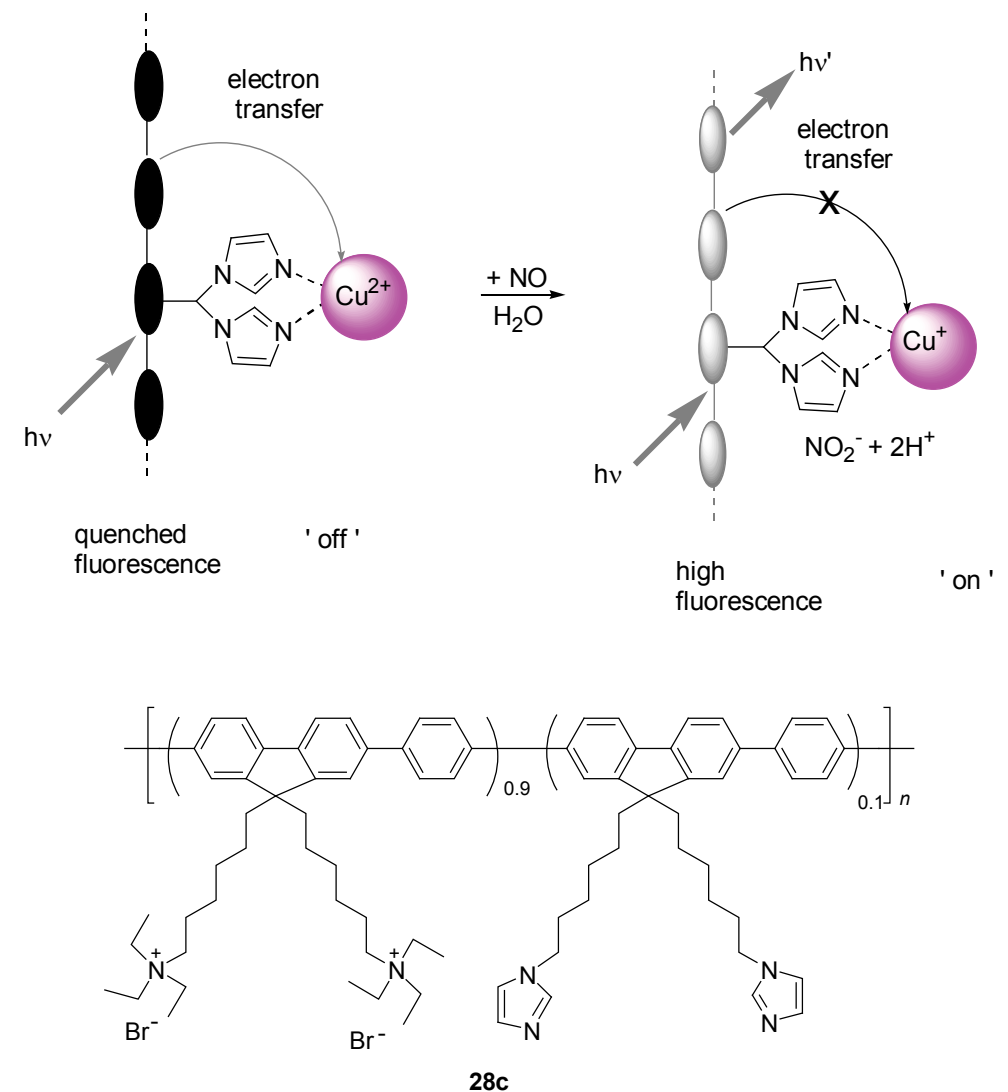

图 2 基于水溶性聚芴衍生物 $\mathbf{2 8 c}$ 的 $\mathrm{NO}$ 检测示意图

Figure 2 Schematic representationof the NO sensor based on the fluorescence turn on of water soluble polyfluorene 28c
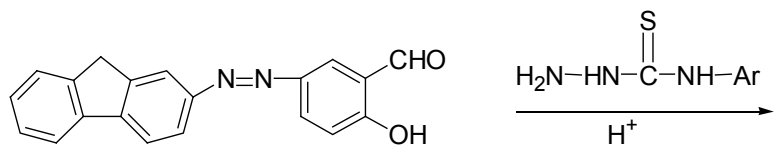

高效、低耐药性的抗疮疾复方药物, 2009 年 4 月 7 日由 美国食品药品管理局(FDA)批准上市. 该药由诺华公司 生产, 用于治疗成人和体质量至少 $5 \mathrm{~kg}$ 的儿童急性无并 发症疮疾感染. 有关其制备方法文献[76]已报道. Atemether-Lumefantrine $(\mathbf{3 0 a} \sim 30 \mathrm{~b})$ 是由抗疮药物蒿甲醚和 苯芴醇按固定质量比 $1: 6$ 组成的复方制剂. 其有效成 分为蒿甲醚, 属青蒿素的衍生物, 具有杀虫速度快、控 制症状迅速的优点, 但复发率高. 苯芴醇是一种合成的 芴乙醇类化合物, 具有较强的灭无性体作用, 毒副作用 小, 安全范围大, 治愈率较高, 但其发挥作用比较缓慢. Atemether-Lumefantrine 的显效速度与蒿甲醚相同, 根 治率高, 克服了蒿甲醚复发率高的缺点, 弥补了苯芴醇 显效慢的不足, 从而达到扬长避短、优势互补的作用.

\section{3 其他领域的应用}

聚芳醚具有优异的耐高温性能、力学性能和绝缘性<smiles>CNC(=S)NC(=S)NN=Cc1cc(N=Nc2ccc3c(c2)Cc2ccccc2-3)ccc1O</smiles>

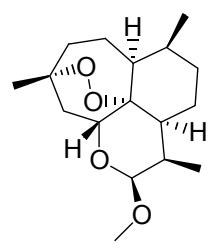

30a Atemeter

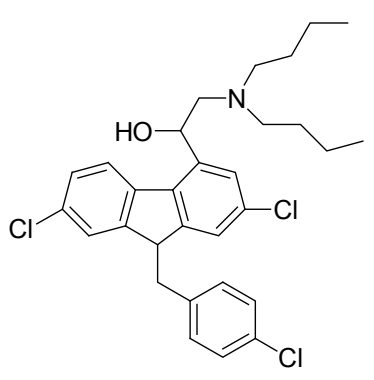

30b Lumefantrine
能, 广泛应用于航天、航空、电子、电器、核能、军工 等尖端领域 ${ }^{[7]}$. 据最新文献[78]报道, 以双酚芴、二烯丙 基双酚 $\mathrm{A}$ 、二氟二苯甲酮为单体合成一种含芴可交联聚 芳基醚酮(PAEK, polyaryletheretherketone) 31, 并对其性 能进行了表征. 得出结论是: 聚合物具有较高的本体粘 度和转化率; 聚合物在交联前具有很好的溶解性, 可以 通过热引发交联固化的方式，制备交联型的含芴 PAEK, 
交联效果随侧链不饱和双键含量的增加而变好, 交联后 的聚合物具有很好的耐溶解性; 聚合物具有良好的耐热 性能, 且 $\mathrm{Tg}$ 随侧链不饱和双键含量的增加而提高 ${ }^{[79]}$.

质子交换膜(PEM, Proton exchange membranes)是燃 料电池的关键组件之一, 其性能与价格直接影响燃料电 池的商业应用发展. 目前商品化的杜邦公司 Nafion 系列 质子交换膜, 聚合物骨架含有 $\mathrm{C}-\mathrm{F}$ 键, 具有良好的化 学和电化学稳定性. 但是 Nafion 膜对甲醇的高渗透率会 降低电池工作效率, 并且由于生产工艺复杂而成本较 高, 因此研制低成本、化学性能良好的质子交换膜一直 深受关注. 聚芳醚酮由于具有良好的化学和电化学稳定 性、机械性能和热稳定性能, 被多篇文献报道用作质子 交换膜, 但其容易被水解和氧化降解. 为了得到更稳定 的聚合物电解质膜, 孟跃中等 ${ }^{[80}$ 曾报道以双酚芴为单 体的磺化聚芴醚酮(32a)作为 PEM, 具有良好的电化学 性能 ${ }^{[81]}$. 将十氟联苯引入与双酚芴聚合, 并以单体磺化 二氟酮调节聚合物的磺化度, 得到部分含氟的聚合物 32b 作为 PEM. 预计 $\mathrm{C}-\mathrm{F}$ 键的引入可以进一步提高 PEM 的稳定性.
近年来很多科学家开始关注以阴离子交换膜(AEM, anion-exchange membranes) 为电解质的碱性燃料电 池 ${ }^{[82,83]}$ ，该种燃料电池与 PEM 燃料电池相比，具有高效 率和低成本等优势, 原因如下: (1)具有良好的氧化还原 反应动力学; (2)可以选择更多的以过渡金属为基础的阴 极催化剂. 但是现有 AEM 的离子导电性和稳定性能都 不如 PEM. 所以科学家致力于开发性能更好的 AEM 材 料. Tanaka 研究小组近期合成了一系列含氨基取代芴类 单元的聚芳醚衍生物 $33 \mathbf{a}^{[84,85]}, \mathbf{3 3} \mathbf{b}^{[86]}$. 研究证实该类聚 合物具有良好的阴离子传导性能; 化学和热稳定性. 扫 描投射电子显微研究证实：该类结构规整的多嵌段共聚 物具有良好的疏水/亲水相分离，以及相互联系的离子 传输通道. 33b 作为离子交换膜表现出很高的氢氧离子 传输性能, 在 $80{ }^{\circ} \mathrm{C}$ 时达到 $144 \mathrm{mS} / \mathrm{cm}$, 比现有文献报道 值都要高; 耐久性检验证实在 $80{ }^{\circ} \mathrm{C}$ 的水中, 连续工作 $5000 \mathrm{~h}$ ，仍然保持良好的离子传输性能，将其用于肼碱 性燃料电池, 在电流密度为 $826 \mathrm{~mA} / \mathrm{cm}^{2}$ 时, 最大功率密 度为 $297 \mathrm{~mW} / \mathrm{cm}^{2}$.

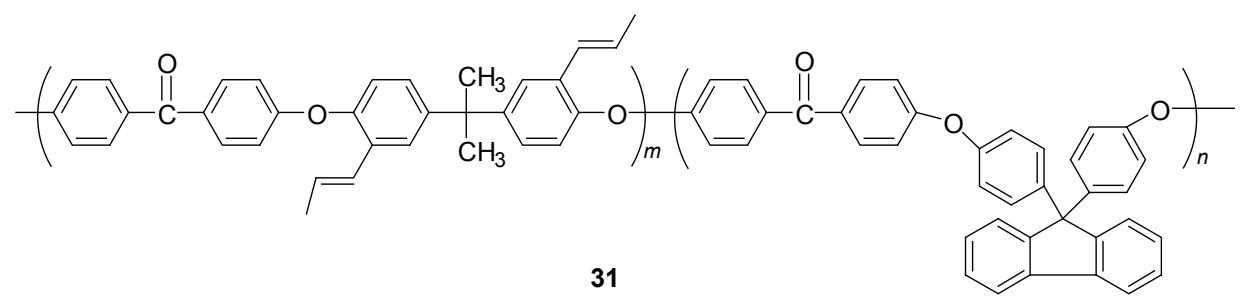

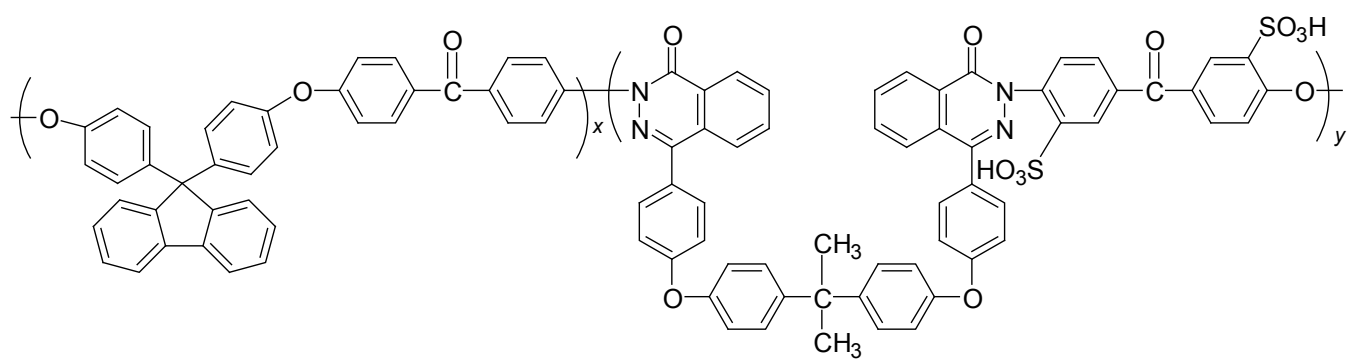

$32 a$<smiles>CC(C)(C)Oc1ccc(C2(c3ccc(Oc4ccc(C(=O)c5ccc(C(C)(C)C)c([N+](=O)[O-])c5)cc4S(=O)(=O)O)cc3)c3ccccc3-c3ccccc32)cc1</smiles>

$32 b$ 


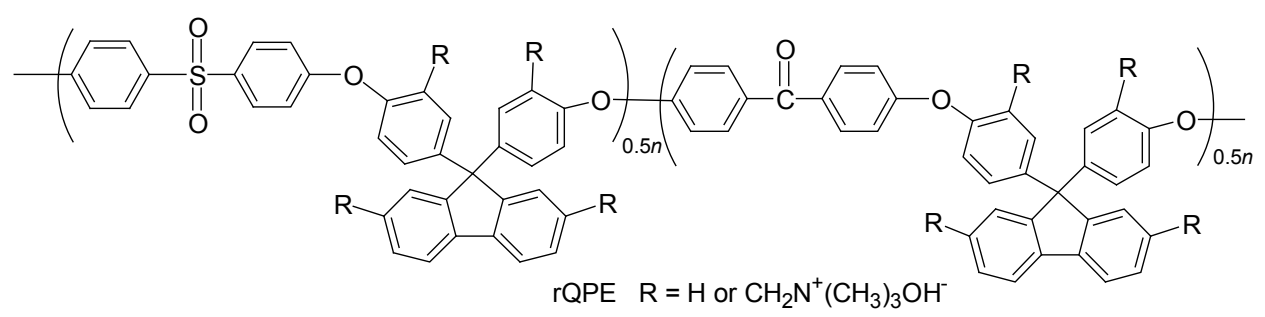

$33 a$

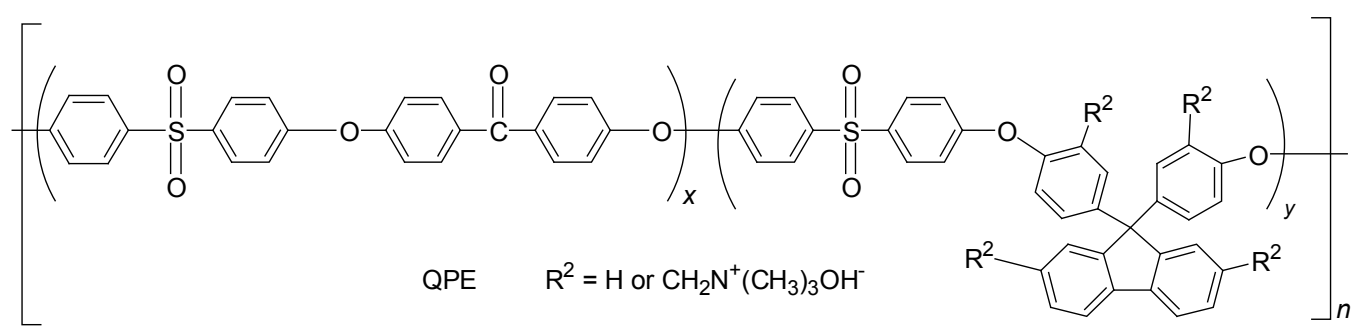

$33 b$

\section{4 结束语}

芴类化合物含有的刚性平面联苯结构、拥有的高荧 光量子效率和能隙、明显的电致发光和光致发光现象、 大的共轭吸收波长以及易于在其刚性的荡环上引入多 种功能基团等, 使得芴类化合物在光电材料、生物、医 药等众多领域已显示出广泛的潜在应用, 相关领域的研 究十分活跃, 并取得了许多重要的研究成果. 尽管如此, 在许多领域还需要进一步深入.

今后芴类衍生物作为有机电致发光材料的研究重 点仍需集中在提高材料发光的饱和纯度、发光效率、材 料对载流子的传输能力以及降低材料启动电压和延长 器件寿命等方面; 对于光致变色材料, 如何解决疲劳现 象直接导致光致变色商品的使用寿命缩短, 商品性价比 降低的问题, 提高市场竞争力是现在急需解决的问题之 一; 茀类衍生物作为太阳能电池材料的研究起步比较 晚, 效率也较低, 想要获得溶解性好、电子亲和能高、 载荷迁移率高等的聚合物太阳能电池仍任重而道远; 芴 类衍生物作为生物传感材料的研究虽然取得了一定的 成果, 但距离临床实际应用还有很多问题需要解决, 需 要进一步研究聚合物生物传感的机理、寻找高效的苂光 能量转移体系, 利用共轭聚合物为探针从多角度深入研 究基因水平上的生命反应过程; 研发结构新颖的人工合 成的芴类化合物作为药物的研究应该得到更多的重视, 随着世界疾病种类日益繁多, 此领域的研究将更为活 跃.

综上所述, 芴类化合物显示出很大的发展潜力和宽 广的潜在应用, 我们有理由相信, 随着化学、物理学、 材料学、生物学和药学等多个学科的发展. 芴类化合物 的研究与开发将更为活跃, 有关芴类化合物的合成及其
在材料、生物、医药的研究与应用比将取得更大的突破, 必将有更多的芴类化合物在有机光电材料、生物、医药 等诸多领域得到实际应用，造福人类.

\section{References}

[1] (a) Schluter, A. D. J. Polym. Sci., Part A: Polym Chem. 2001, 39, 1533.

(b) Zhong, H. L.; Lai, H.; Fang, Q. J. Phys. Chem. C 2011, 115, 2423.

(c) Sun, J.; Lai, H.; Zhong, H. L.; Fang, Q. Thin Solid Films 2011, 519,7772 .

[2] Stork, M.; Gaylord, B. S.; Heeger, A. J.; Bazan, G. C. Adv. Mater. 2002, 14, 3613

[3] Svensson, M.; Zhang, F. L.; Veenstra, S. C. Adv. Mater. 2003, 15(12), 988

[4] Cliferson, T.; Aurore, L.; Kevin, B. Macromolecules 2011, 44, 4012.

[5] Pei, J.; Liu, X. L.; Huang, W. Macromolecules 2003, 36, 323.

[6] Liu, B.; Yu, W. L.; Huang, W. Macromolecules 2002, 35, 4975.

[7] Anthony, J. E. Chem. Rev. 2006, 106, 5028.

[8] Okamoto, T.; Bao, Z. J. Am. Chem. Soc. 2007, 129, 10308

[9] Snaith, H. J.; Greenham, N. C.; Friend, R. H. Adv. Mater. 2004, 16, 1640.

[10] Werts, M. H. W.; Gmouh, S.; Mongin, O.; Pons, T.; Desce, M. $J$. Am. Chem. Soc. 2004, 126 (50): 16294

[11] Zhou, X. H.; Yan, J. C.; Pei, J. Macromolecules 2004, 37, 7078.

[12] List, E. J. W.; Guentner, R.; Scherf, U. Adv. Mater 2002, 14, 374.

[13] (a) Kraft, A.; Grimsdate, A. C.; Homes, A. B. Angew. Chem., Int. Ed. 1998, 37, 402

(b) Goel, A.; Chaurasia, S.; Kumar, V.; Manoharan, S.; Anand, R. S. CN 102046598, 2009 [Chem. Abstr. 2009, 151, 458971].

[14] Andrew, C.; Grimsdale, A. H.; Khai, L. C.; Rainer, E. M.; Pawel, G. J.; Andrew, B. H. Chem. Rev. 2009, 109, 897.

[15] Zhang, L.; Lin, Z. Q.; Gu; J. F.; Huang, W. Acta Phys. Chim. Sin. 2010, 26(7), 1934 (in Chinese).

(张龙, 林宗琼, 顾菊芳, 黄维, 物理化学学报 2010, 26(7), 1934.)

[16] Jiang, Z. Q.; Liu, Z. Y.; Yang, C. L.; Zhong, C.; Qin, J. G.; Yu, G.; Liu, Y. Q. Adv. Funct. Mater. 2009, 19, 3987. 
[17] Zhen, C. G.; Chen, Z. K.; Liu, Q. D.; Dai, Y. F.; Shin, R. Y. C.; Chang, S. Y.; Kieffer, J. Adv. Mater. 2009, 21, 2425.

[18] Liu, B.; Yu, W. L.; Lai, Y. H.; Huang, W. Chem. Commun. 2000, 551.

[19] Guo, J. G.; Cui, Y. M.; Lin, H. X.; Xie, X. Z.; Chen, H. F. J. Photochem. Photobiol., A: Chem. 2011, 219, 42.

[20] Huang, C. W.; Tsai, C. L.; Liu, C. Y.; Jen, T. H.; Yang, N. J.; Chen, S. A. Macromolecules 2012, 45, 1281.

[21] Deng, J. Y.; Liu, Y.; Wang, Y. F.; Tan, H.; Zhang, Z. Y.; Lei, G. T.; Yu, J. T.; Zhu, M. X.; Zhu, W. G.; Cao, Y. Eur. Polym. J. 2011, 47, 1836.

[22] Yildirim, M.; Kaya, I. Synth. Met. 2011, 161, 13.

[23] Xiao, L. X.; Hu, S. Y.; Kong, S.; Chen, Z. J.; Qu, B.; Gong, Q. H. Acta Phys.-Chim. Sin. 2011, 27(4), 977 (in Chinese). (肖立新, 胡双元, 孔胜, 陈志坚, 曲波, 龚旗煌, 物理化学学报 2011, 27(4), 977.)

[24] Wang, K. L.; Leung, M. K.; Hsieh, L. G.; Chang, C. C.; Lee, K. R.; Wu, C. L.; Jiang, J. C.; Tseng, C. Y.; Wang, H. T. Org. Elec. 2011, $12,1048$.

[25] Jiang, H. J.; Huang, W. Prog. Chem. 2008, 20(4), 539 (in Chinese). (姜鸿基, 黄维, 化学进展 2008, 20(4), 539.)

[26] Luo, J.; Li, X. Z.; Chen, J. W.; Huang, F.; Cao, Y. Synth. Met. 2011, 161, 1982.

[27] Wang, L. X.; Jing, X. B.; Wang, F. S. Acta Polym. Sinica 2009, (10), 980 (in Chinese). (王利祥，景遐斌，王佛松，高分子学报 2009, (10), 980.)

[28] Tu, G. L.; Mei, C. Y.; Zhou, Q. G.; Cheng, Y. X; Wang, L. X.; Ma, D. G., Jing, X. B.; Wang, F. S. Adv. Funct. Mater. 2006, 16, 101.

[29] Zhang, Y.; Hou, Q.; Zheng, S. W.; Li, S. T.; Fan, G, H. J. South China Normal Univ. (Nat. Sci. Ed.) 2009, (4), 57.

(章勇, 侯琼, 郑树文, 李述体, 范广涵, 华南师范大学学报(自 然科学版) 2009, (4), 57. )

[30] Ho, J. S.; Lee, S. M.; Lee, J. Y.; Choi, B. H.; Moon, D. K. Synth. Met. 2011, 161, 2451.

[31] Hsieh, B. Y.; Chen, Y. J. Polym Sci., Part A: Polym Chem. 2008, 46, 3703.

[32] Ouyang, X. H; Wang, G. R; Zeng, H. P.; Zhang, W. M.; Li, J. J. Organomet. Chem. 2009, 694, 3511.

[33] Wang, T.-T.; Zeng, G.-C.; Zeng, H.-P.; Liu, P.-Y.; Wang, R.-X.; Zhang, Z.-J.; Xiong, Y.-L. Tetrahedron 2009, 65, 6325.

[34] Zeng, H.-P.; Wang, G.-R.; Zeng, G.-C.; Li, J. Dyes Pigm. 2009, 83, 155.

[35] Yuen, M. Y.; Kui, S. C. F.; Low, K. H.; Kwok, C. C.; Chui, S. S. Y.; Ma, C. W.; Zhu, N. Y.; Che, C. M. Chem. Eur. J. 2010, 16, 14131.

[36] Ahmed, S. A. M.; Al-Raqa, S. Y. J. Phys. Org. Chem. 2011, 24, 173.

[37] Ahmed, S. A. M. Tetrahedron Lett. 2010, 51, 730.

[38] Ahmed, S. A. M. Tetrahedron 2009, 65, 1373.

[39] Li, C. H.; Zheng, C. M.; Zeng, H. P. Chin. J. Org. Chem. 2011, 31, 659 (in Chinese). (李财花, 郑春梅, 曾和平, 有机化学 2011, 31, 659.)

[40] Marco, S.; Andres, J. J. Am. Chem. Soc. 2010, 132, 8372.

[41] Dürr, H. Angew. Chem., Int. Ed. Engl. 1989, $28,413$.

[42] Miller, M. J.; Wei, S. H.; Parker, I.; Cahalan, M. D. Science 2002, $296,1869$.

[43] Zhou, W. H.; Kuebler, S. M.; Braun, K. L.; Yu, T. Y.; Cammack, J. K.; Ober, C. K.; Perry, J. W.; Marder, S. R. Science 2002, 296, 1106.

[44] Parthenopoulos, D. A.; Rentzepis, P. M. Science 1989, 245, 843.

[45] Bhawalkar, J. D.; Kumar, N. D.; Zhao, C. F.; Prasad, P. N. J. Clin. Laser Med. Surg. 1997, 15, 201.

[46] Perry, J. W.; Mansour, K.; Lee, I. Y. S.; Wu, X. L.; Bedworth, P. V.; Chen, C. T.; Ng, D.; Marder, S. R.; Miles, P.; Wada, T.; Tian, M.;
Sasabe, H. Science 1996, 273, 1533.

[47] Thivierge, C.; Loudet, A.; Burgess, K. Macromolecules 2011, 44, 4012.

[48] Belfield, K. D.; Morales, A. R.; Kang, B. S.; Hales, J. M.; Hagan, D. J.; Van Stryland, E. W.; Chapela, V. M.; Percino, J. Chem. Mater. 2004, 16, 4634.

[49] Yao, S.; Belfield, K. D. J. Org. Chem. 2005, 70, 5126.

[50] Belfield, K. D.; Yao, S.; Bondar, M. V. Adv. Polym. Sci. 2008, 213, 97.

[51] Yanez, C. O.; Andrade, C. D.; Belfield, K. D. Chem. Commun. 2009, 827.

[52] Moura, G. L. C.; Simas, A. M. J. Phys. Chem. C 2010, 114, 6106.

[53] Andrade, C. D.; Yanez, C. O.; Rodriguez, L.; Belfield, K. D. J. Org. Chem. 2010, 75, 3975.

[54] Wang, H. L.; Li, Z.; Shao, P.; Qin, J. G.; Huang, Z. L. J. Phys. Chem. B 2010, 114, 22.

[55] Ouyang, X. H.; Huo, Y. P. Appl. Phys. A 2011, 105, 891

[56] Scherf, U.; List, E. J. W. Adv. Mater. 2002, 14, 477.

[57] Shen, P.; Tang, Y. H.; Jiang, S. H.; Chen, H. J.; Zheng, X. Y.; Wang, X. Y.; Zhao, B.; Tan, S. T. Org. Electron. 2011. 12, 125.

[58] Sahu, D.; Padhy, H.; Patra, D.; Yin, J. F.; Hsu, Y. C.; Lin, J. T.; Lu, K. L.; Wei, K. H.; Lin, H. C. Tetrahedron 2011, 67, 303.

[59] Liu, B. J.; Hu, W.; Chen, C. H. Polymer 2004, 45(10), 3241.

[60] Zhang, F. L.; Perzon, E.; Wang, X. J. Adv. Funct. Mater. 2005, 15 (5), 745.

[61] Zhang, F. L.; Mammo, W.; Andersson, L. M. Adv. Mater. 2006, 18 , 2169.

[62] Hou, Q.; Zhang, Y.; Li, F. Organometallics 2005, 24, 4509.

[63] Schulz, G. L.; Holdcroft, S. Chem. Mater. 2008, 20, 5351.

[64] Liu, L.; Ho, C. L.; Wong, W. Y.; Cheung, K. Y.; Fung, M. K.; Lam, W. T.; Djurisic, A. B.; Chan, W. K. Adv. Funct. Mater. 2008, 18. 2824.

[65] Wang, S.; Janice, W. H.; Guillermo, C. B. Org. Lett. 2005, 7(10), 1907.

[66] Xing, C. F.; Xu, Q. L.; Tang, H. W.; Liu, L. B.; Wang, S. J. Am. Chem. Soc. 2009, 131, 13117.

[67] Feng, F. F.; He, F.; An, L. L.; Wang, S.; Li, Y. L; Zhu, D. B. $A d v$. Mater. 2008, 20, 2959.

[68] Feng, X. L.; Yang, G. M.; Liu, L. B.; Yang, Q.; Wang, S.; Zhu, D. B. Adv. Mater. 2012, 24, 637.

[69] Feng, F. F.; Tang. Y. L.; He, F.; Yu, M. H.; Duan, X. R.; Wang, S.; Li, Y. L.; Zhu, D. B. Adv. Mater. 2007, 3490.

[70] Stork, M.; Gaylord, B. S.; Heeger, A. J.; Bazan, G. C. Adv Mater. 2002, 14, 361

[71] He, F.; Y. L.; Yu, M. H.; Wang, S.; Li, Y. L.; Zhu, D. B. Adv. Funct. Mater. 2006, 16, 91 .

[72] Zhou, X. H.; Yan, J. C.; Pei, J. Macromolecules 2004, 37, 7078.

[73] Xing, C. F.; Yu, M. H.; Wang, S.; Shi, Z.; Li, Y. L.; Zhu, D. B. Macromol. Rapid Commun. 2007, 28, 241.

[74] Shao, Y. J. Hubei Univ. Nat. 2009, 27(2), 152 (in Chinese). (邵宇, 湖北民族学院学报 2009, 27(2), 152.)

[75] Zhang, W. X.; Zhang, Y. M.; Wei, T. B. Appl. Chem. 2008, 25(12), 1460 (in Chinese). (徐维霞, 张有明, 魏太保, 应用化学 2008, 25(12), 1460.)

[76] Zhang, F. L.; Mammo, W.; Andersson, L. M. Adv. Mater. 2006, 18, 2169.

[77] Wang, X. J.; Perzon, E.; Delgado, J. L. Appl. Phys. Lett. 2004, 85(21), 5081.

[78] Ding, F. C.; Chen, Q. S.; Lai, S. L.; Li, X. Y. China Plastics 2011, 25(5), 36 (in Chinese).

(丁富传，陈清松，赖寿莲，李晓燕，中国塑料 2011，25(5), 36.)

[79] Luminita, M.; Elena, P.; Mariana, D. D. Eur. Polym. J. 2011, 47, 
1284.

[80] Han, D. M.; Shu, D.; Wang, S. J.; Xiao, M.; Meng, Y. Z. Memb. Sci. Technol. 2010, 30(1), 5 (in Chinese).

(韩东梅, 舒东, 王拴紧, 肖敏, 孟跃中, 膜科学与技术 $\mathbf{2 0 1 0}$, 30(1), 55.)

[81] Tian, S. H.; Shu, D.; Meng, Y. Z. Memb. Sci. Technol. 2008, 28(2), 18 (in Chinese).

(田双红, 舒东, 孟跃中, 膜科学与技术 $2008,28(2), 18$.)

[82] Vorcoe, J. R.; Slade, R. C. T. Fuel Cells 2005, 2, 187.
[83] Xu, T. J. Membr. Sci. 2005, 263, 1 .

[84] Tanaka, M.; Koike, M.; Miyatake, K.; Watanabe, M. Macromolecules 2010, 43, 2657

[85] Tanaka, M.; Koike, M.; Miyatake, K.; Watanabe, M. Polym. Chem. 2011, 2, 99.

[86] Tanaka, M.; Fukasawa, K.; Nishino, E.; Yamaguchi, S.; Yamada, K.; Tanaka, H.; Bae, B.; Miyatake, K.; Watanabe, M. J. Am. Chem. Soc. 2011, 133, 10646. 